\title{
EL PERIODISMO DE \\ EL LIBERAL \\ ANTE LAS ELECCIONES: \\ PRECARIA GUÍA PARA \\ EL LECTOR-ELECTOR
}

THE JOURNALISM OF

EL LIBERAL BEFORE

THE ELECTIONS:

POOR GUIDE FOR THE

READER-VOTER

Por:

Piedad Ruiz Echeverry ${ }^{1}$

Profesora asociada Dpto. de Comunicación Social

Universidad del Cauca

pruiz@unicauca.edu.co

Resumen: El estudio de 312 notas periodísticas del diario El Liberal, relativas a los procesos de elección popular de alcaldes en Popayán durante los años 1988, 1994 y 2003, permitió un análisis histórico sobre el tratamiento periodístico del tema de las elecciones políticas. Partiendo de que la información es un bien público, se asume que el tema electoral debe tratarse en los medios para promover una opinión pública con criterios claros de decisión política, cosa que no sucede según los hallazgos. El análisis de resultados se hizo a partir de una base de datos que incluyó variables como autoría, géneros, contexto, recursos visuales, candidatos mencionados, espacio, temas o publicidad política. Con ello se estudiaron dos grandes aspectos: el uso de recursos periodísticos y el equilibrio informativo, lo cual permitió concluir la ausencia de una tendencia clara hacia el mejoramiento del tratamiento noticioso de las elecciones por parte del periódico en torno a los procesos electorales.

Palabras clave: Tratamiento periodístico, equilibrio informativo, Elecciones, El Liberal, Popayán.

\begin{abstract}
The study of 312 news stories from the newspaper El Liberal, concerning to process of election of mayors in Popayán during the years 1988, 1994 and 2003, allowed the historical analysis of press coverage given to political issues of elections. Assuming that information is a public good, it is assumed that the election issue should be treated in the media to promote public opinion with clear criteria for decision. The analysis of results was done from a database that included variables such as authorship, genre, context, visual resources, candidates mentioned, space, issues or political advertising. This studied had two major aspects: the use of newspaper resources and informational balance, which allowed concluding the absence of a clear trend towards improving election news coverage from the newspaper about the electoral process.
\end{abstract}

Keywords: Press coverage, news balance, Elections, El Liberal, Popayán. 


\section{Introducción}

Este informe presenta los resultados de un trabajo de investigación desarrollado durante el año 2012 y titulado: "Análisis histórico del tratamiento periodístico a la información electoral en el diario El Liberal. Tres momentos de estudio. (1988, 1994 y 2003)”. El trabajo hace parte de la actividad del grupo de investigación del Departamento de Comunicación Social llamado "estudios e investigaciones en comunicación social", y contó con el respaldo técnico de la Misión de Observación Electoral, MOE y la asistencia de investigación del estudiante Diego Alfonso Imbachí Garcés.

La investigación se propuso revisar tres procesos electorales no incluidos por la $\mathrm{MOE}$ en sus procesos de seguimiento a medios, realizados en los últimos cinco años, para tratar de obtener una perspectiva general sobre el ejercicio periodístico en torno a las elecciones de alcalde de Popayán, desde la instauración de la elección popular de alcaldes en el año 1987, con la expedición de la ley 078 de 1986.

A partir de las experiencias previas desarrolladas por una plataforma de universidades a nivel nacional coordinadas por la MOE, se definió una base de datos constituida por 24 variables. En total se consignaron 312 notas periodísticas distribuidas así: 68 en el año 1988, 121 en el año 1994, y 123 en el año 2003. Con estos datos capturados y sistematizados, se buscó establecer la presencia o no de una tendencia histórica de El Liberal hacia un mejor cubrimiento periodístico de la información política, en particular aquélla relativa a los procesos electorales de alcaldes.

Con Javier Darío Restrepo, consideramos también aquí que "la información es un servicio tan necesario para la sociedad, como para el cuerpo humano el agua, la luz o el aire. Son servicios que no se pueden suspender y los encargados de suministrarlos saben que deben garantizarlos porque es la vida humana la que depende de ese suministro" (Restrepo, 2010). Por ello se procuró caracterizar tanto el manejo periodístico de la información, como la contribución del diario El Liberal a una opinión pública debidamente formada. Esto se hizo a partir de criterios de equilibrio y profundidad en el manejo de las notas periodísticas, para establecer si hay por parte del periódico y en qué medida, una contribución a la democracia, a partir del tipo de tratamiento que se le da a un bien público como la información electoral. 
En primer lugar el informe presentará el análisis de los datos relativos al adecuado uso de los recursos periodísticos, de acuerdo con los criterios establecidos internacionalmente para el desarrollo del oficio, tales como: uso de diversas fuentes de información, utilización de variedad de géneros periodísticos, profundidad en el tratamiento de la información, continuidad en el desarrollo de la noticia, complemento de la información con el uso de recursos visuales y coherencia interna de los contenidos de las notas periodísticas.

En segundo lugar, se expondrá el análisis relacionado con el equilibrio informativo del tratamiento periodístico de los procesos electorales, a partir de variables más directamente relacionadas con los candidatos, los partidos, y los contenidos programáticos expuestos en El Liberal durante los tres procesos electorales. Valga decir que el trabajo comparativo entre los períodos del estudio busca establecer la tendencia de El Liberal hacia un mejor o más deficiente cubrimiento periodístico de la información política, en particular aquélla relativa a los procesos electorales.

\section{Tratamiento o uso de recursos periodísticos}

Se presenta a continuación el análisis relativo a las variables: Sección de la información, Autoría de la información, Recursos visuales, Relación titular/contenido, Géneros periodísticos, Contextualización y Fuentes de información.

\subsection{Sección de la información}

Al revisar la distribución en frecuencias de la información en las distintas secciones del periódico en los tres años del estudio, encontramos que en 1988, primer año de estudio, la información relativa a la primera elección popular de alcaldes, se consignó en El Liberal básicamente en tres secciones, las cuales son en su orden: las páginas local o regional (21\%), la primera página( 20\%), y en tercer lugar las páginas editoriales (15\%), siendo los otros espacios del periódico secundariamente utilizados para presentar a los lectores la información relativa al proceso electoral. En los años 1994 y 2003 en cambio, se encuentra una modificación en la tendencia, ya que la información electoral se expone en su inmensa mayoría en la página política, ocupando lugares muy secundarios los editoriales, y en proporciones poco relevantes otras secciones como primera página, informes especiales, páginas nacionales e internacionales locales o regionales, etc.

Con lo anterior podemos ver una utilización más clara de las distintas secciones del periódico por parte del diario monitoreado en los últimos dos períodos del estudio, ya que se considera que la página política es el espacio idóneo para ubicar la información relativa al proceso electoral. No obstante es interesante destacar la proporción que en segundo lugar ocupa en los tres años de estudio la ubicación de esta información en los editoriales del periódico, en los cuales se consigna la opinión expresa de la directiva del medio de comunicación. También es pertinente resaltar la relevancia que se da al proceso electoral en el año 1988, toda vez que una importante proporción de la información producida en torno al mismo, se destacó en la primera página, lo cual en buena medida puede explicarse por el hecho de ser este año la primera ocasión en la que se desarrollaron las elecciones populares de alcaldes en el país. 
No obstante, como observación general, consideramos que la disgregación de secciones para la exposición de información sobre las elecciones, es muestra de aquello que Fontcuberta denomina periodismo de mosaico, en contraposición al periodismo de sistema, para referirse al hecho de que hoy en día en los periódicos "...en el mejor de los casos, se ofrecen en áreas o secciones perfectamente compartimentadas, son la menor relación las unas con las otras; en el peor, que se arrojan a las páginas sin orden ni concierto.."(...) muchos medios han seguido una política errática cuando no contradictoria, a la hora de vertebrar internamente su temario"(Fontcuberta, 2006, pag 33).

El gráfico de distribución porcentual que se presenta abajo ilustra con mayor claridad año a año la tendencia a la concentración de la información en las páginas de la sección política, siendo notoria la diferencia entre del tratamiento dado en 1988 y el tratamiento en 1994 y 2003.

\section{\% Distribución de la información electoral según sección y periodo}

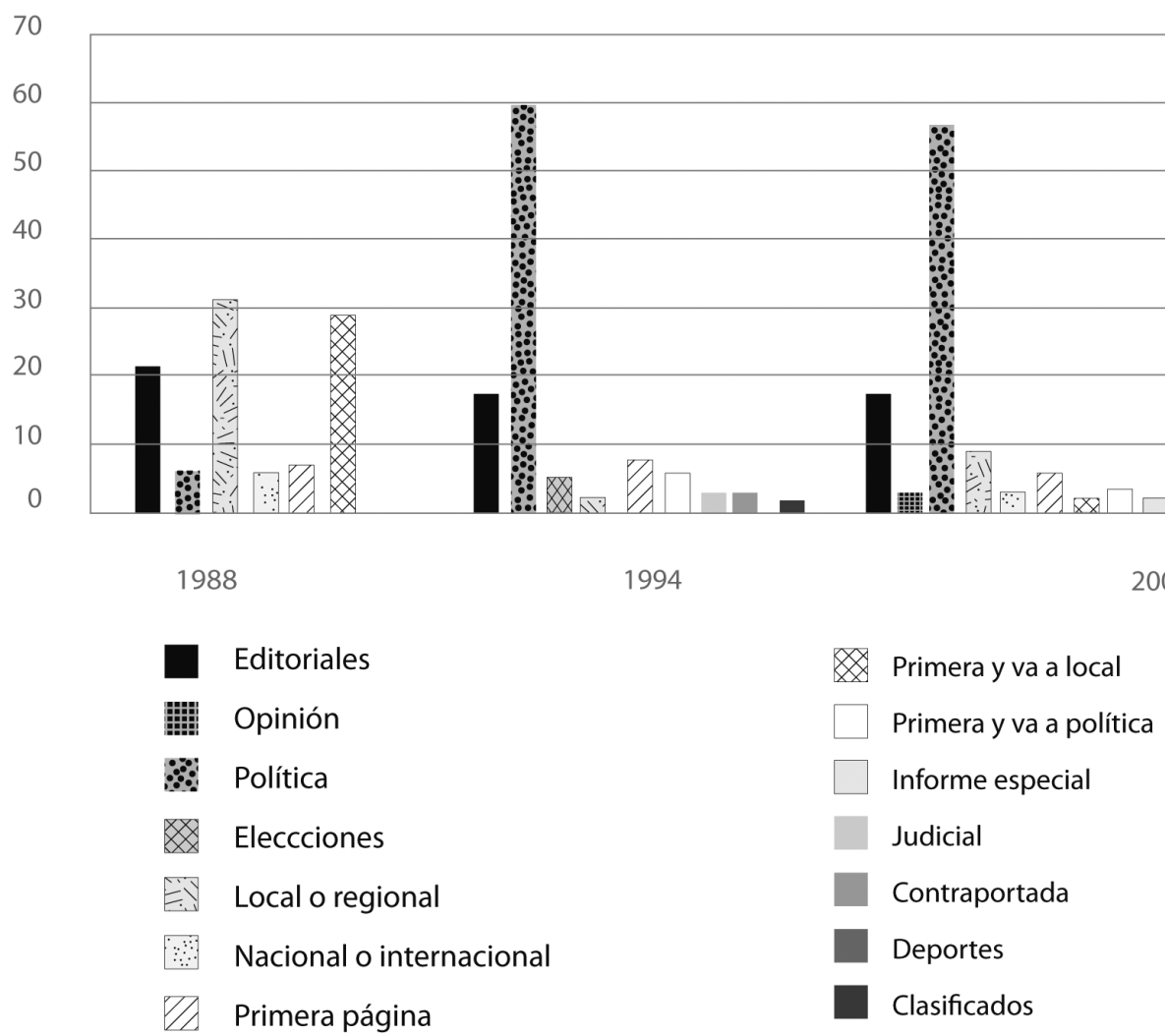




\subsection{Autoría de la información}

Comparando los tres períodos de estudio se observó en los datos absolutos que en las notas periodísticas sobre las elecciones de alcaldes en Popayán, hubo una altísima frecuencia de información cuya autoría no era identificada expresamente por el medio impreso (33 notas en 1988, 70 en 1994 y 82 en 2003). Sin embargo, entre el primer año y los últimos dos, hay un incremento del número de notas sobre la temática electoral, y un decrecimiento en la cantidad de ellas que fueron firmadas por periodistas del periódico. La autoría de la información por parte de agencias de prensa se mantiene en términos generales en la misma cantidad de notas, mientras llama la atención la mayor utilización de editorialistas invitados en el primer año del estudio, lo cual sugiere nuevamente la importancia asignada en ese primer momento al evento de la elección popular de alcaldes, lo cual ameritaría para el periódico la convocatoria de expertos o personajes de la política regional o local a generar notas y comentarios relativos a dicho proceso.

\% Autoría de la información y periodo

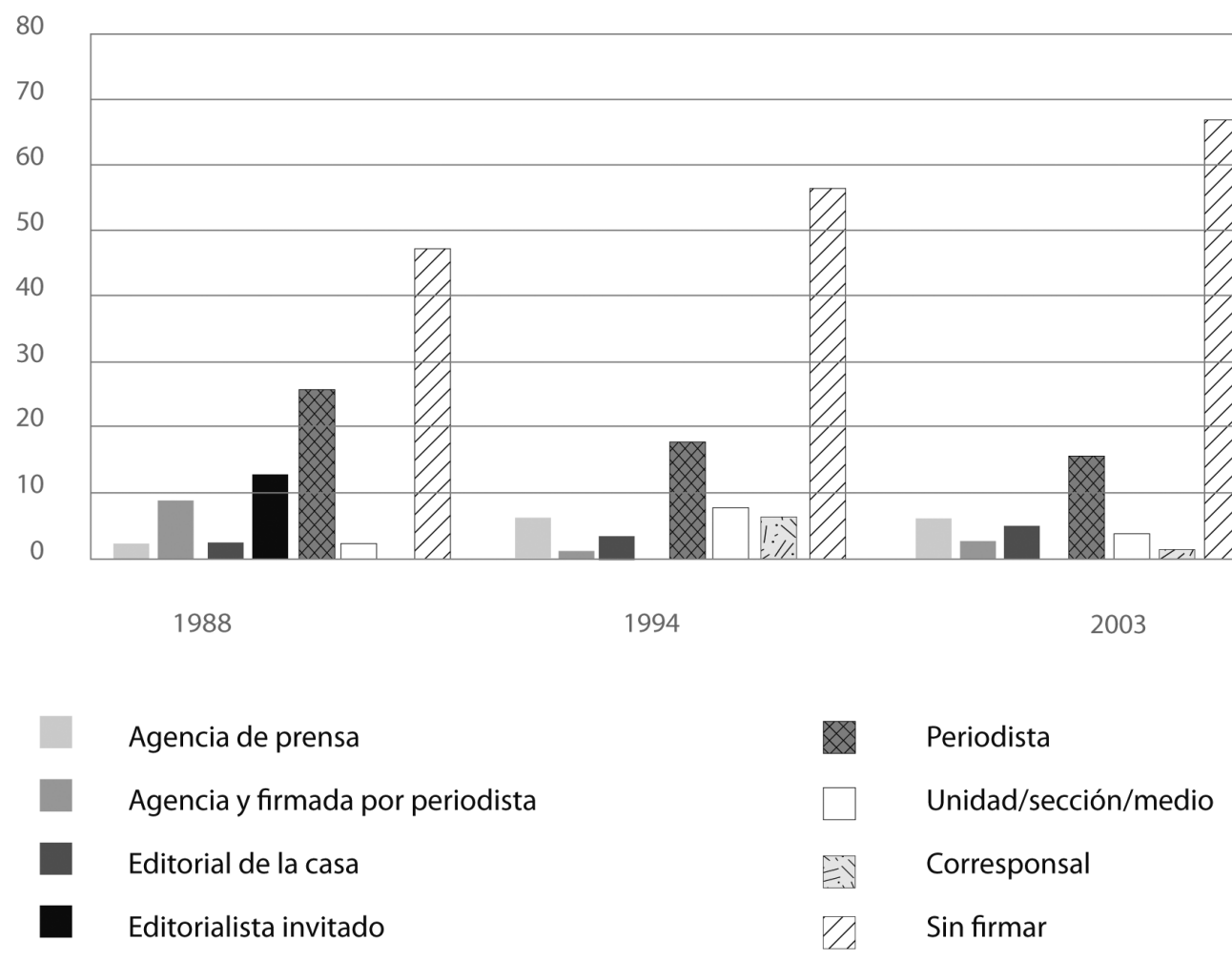

Gráfico 2. 
Al revisar los porcentajes de la distribución de la autoría de la información año a año, se hace más evidente la menor presencia con el paso del tiempo de las notas firmadas, es decir con autoría claramente identificada. Una hipótesis a confirmar sobre las causas de este fenómeno, podría ser el hecho innegable de que el ejercicio de la profesión ha ido convirtiéndose poco a poco en un riesgo para la integridad física y la seguridad de los periodistas, debido a que el desarrollo de ciertos temas de la información han generado una ola de amenazas y atentados contra estos profesionales de manera creciente en los últimos años, lo que ha llevado a tomar como medida de precaución el anonimato frente a la publicación de contenidos que, como en el caso de la política, pueden considerarse de mayor riesgo ${ }^{2}$.

No obstante, si se tiene en cuenta que el periódico El Liberal no se ha caracterizado en su tratamiento de la información política por ser un diario particularmente crítico hacia la tradición partidista del país, también cabría la explicación de una creciente despreocupación por la asunción de la responsabilidad editorial por parte de los periodistas frente a la información que se proporciona al público.

\subsection{Recursos visuales: uso, tipo y coherencia}

Según el Manual de estilo de la Sociedad Interamericana de Prensa, "además de las fotografías, un periódico lleva otro material de ilustración: dibujos, retratos a mano, gráficos, cuadros estadísticos, curvas gráficas, etc" (Martínez y Santamaría, 1996, pág 146).). Dichos elementos contribuyen a complementar de manera amplia la información escrita. En nuestro caso, la investigación mostró que el análisis de esta variable no permitió identificar una clara tendencia sobre el uso de recursos gráficos y visuales en el transcurso del tiempo, ya que encontramos en el año 1988 y en el año 2003 fue menor la cantidad de notas periodísticas relativas al proceso electoral de alcalde de Popayán que se acompañaron de recursos visuales, que la cantidad de notas solamente escritas; mientras tanto, el período intermedio tiene un número ligeramente mayor de notas periodísticas con despliegue de complementos visuales, referidos básicamente al uso de fotografías.

Uso o no de recursos visuales en la información electoral, según periodo

100

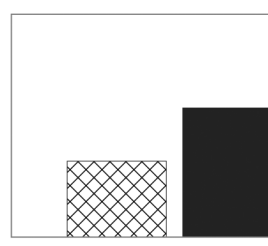

1988

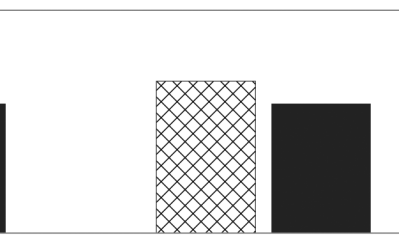

1994

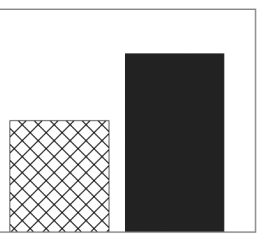

$\mathrm{Si}$

No

Gráfico 3. 
Al revisar la distribución porcentual año a año encontramos que en aquellas notas en las que se utilizaron recursos visuales de apoyo, los tres períodos estudiados se caracterizan por los recursos considerados más elementales, como son las fotografías. Las infografías, gráficos y tablas estadísticas fueron utilizadas en mucha menor proporción, destacándose el primer año de elección popular de alcaldes como el año en que el periódico hizo un mayor despliegue de variedad de recursos visuales complementarios a la información escrita. Entre tanto, en el año 1994 prácticamente sólo hubo fotografías, lo cual se corrigió para el año 2003, implementando nuevamente el uso aunque en pequeña proporción, de infografía, gráficos y tablas estadísticas, lo cual ofrece una mayor profundidad a la información.

\section{\% Información electoral según recursos visuales usados por periodo}

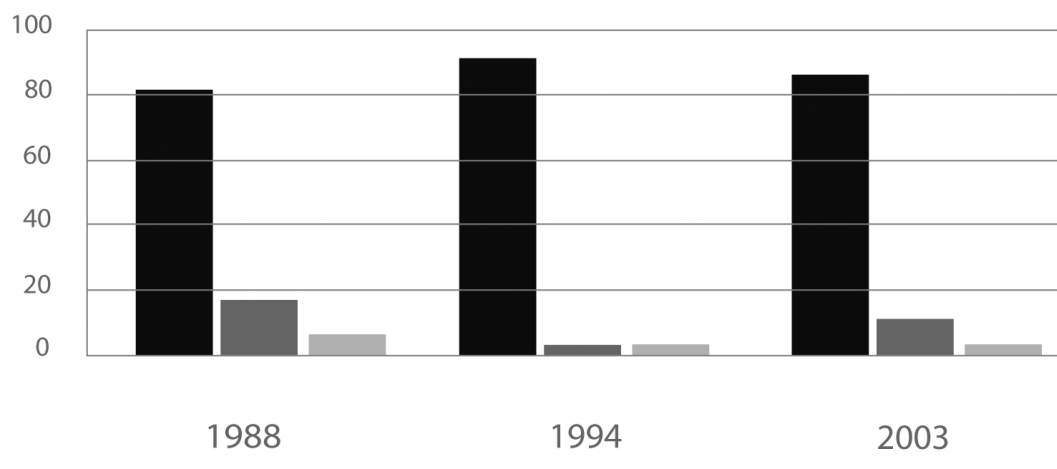

Gráfico 4.

Otra de las variables analizadas fue la coherencia entre los recursos visuales y el contenido de la información. Encontramos que en 1994, año caracterizado por una menor proporción de uso de recursos visuales y dedicados casi exclusivamente a las fotografías, el cubrimiento del proceso electoral de alcaldes tuvo en el tratamiento periodístico de dichos recursos una mayor coherencia con la información escrita de cada una de las notas, al ser información complementaria y un menor carácter de distorsión que en los otros dos períodos.

En 1988 en cambio, se destaca la proporción de notas cuyos recursos visuales no tienen relación con la información escrita, mientras el año 2003 tuvo una distribución porcentual similar entre los recursos visuales que distorsionaron y aquellos que complementaron la información escrita relativa al proceso electoral de alcaldes. 


\section{$\%$ Coherencia entre los recursos visuales e información por periodo}

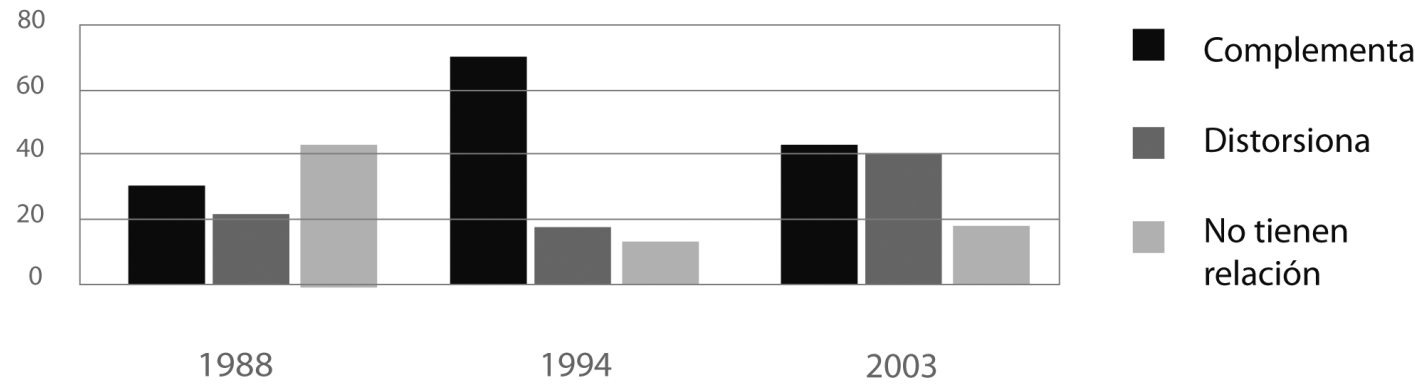

\section{Gráfico 5.}

Con los datos anteriores, relativos al uso o no de recursos visuales, el tipo de recursos visuales utilizados y la coherencia o no entre ellos y la información escrita, encontramos que no podemos hablar de una tendencia clara en el periódico hacia una mejor utilización de las fotografías, las infografías y demás información gráfica complementaria. Cada período fue distinto al otro, sin que se puedan rastrear evidencias en torno a una clara directiva por parte del periódico en torno al asunto.

\subsection{Relación entre titular y contenido de la nota}

La SIP considera que "La función práctica de los titulares de los periódicos es triple: por un lado, sirven para identificar los textos que encabezan; por otro lado sirven para distinguir los textos entre sí, mediante un mecanismo de ordenación, jerarquización y clarificación: en tercer lugar estos encabezamientos sirven también para despertar el interés de los lectores" (Martínez y Santamaría: 1996, pág 148). En el estudio realizado, encontramos sin embargo, que en el caso de El Liberal, la relación explícita entre los titulares y los contenidos o desarrollos informativos de las notas relativas al proceso electoral de alcaldes, ha tendido a decrecer con los años y se ha dado en cambio un crecimiento importante de una relación apenas implícita entre titulares y contenidos.

El crecimiento de la cantidad de notas en las que no hay relación entre titulares y contenidos, da cuenta de un claro descuido editorial por parte del periódico monitoreado. Mientras tanto, el incremento de la relación implícita no necesariamente representa ese mismo descuido, sino que podría significar un cambio en el estilo de la redacción, en el sentido de ser menos expreso en la relación, para buscar unos titulares apenas sugerentes, en procura de atraer la atención del lector. 
Relación entre titular y contenido de la nota, por periodo

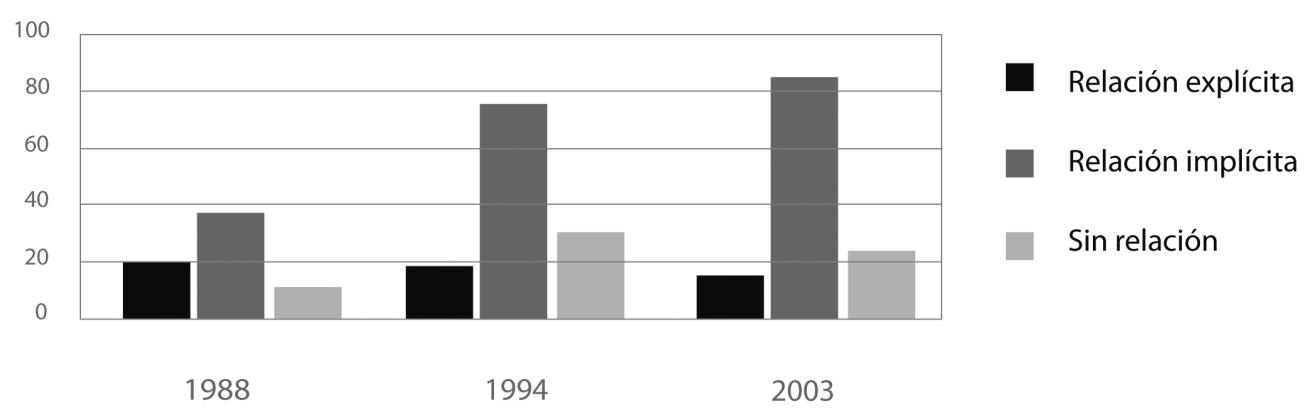

Gráfico 6.

Ahora bien, cuando se hace la comparación a partir de la distribución porcentual de los datos sobre la relación entre el titular y el contenido de la nota en los tres años del estudio, encontramos que no hay variaciones en relación con el análisis a partir de las frecuencias, ya comentado en el párrafo anterior.

\subsection{Géneros periodísticos}

114 En 1988 el periódico El Liberal ofreció información sobre el proceso electoral de alcalde de Popayán básicamente a partir del género de la noticia, el cual se utilizó en cerca de la mitad de las notas periodísticas registradas, seguida en importancia por los editoriales, la voz oficial del periódico, como género privilegiado para referirse a dicho proceso. También las columnas de opinión fueron destacadas en este año, mostrando un abierto interés por expresar la perspectiva del periódico y de sus periodistas. Secundariamente se destacó el uso de los perfiles, como género para la descripción de los rasgos más importantes de los candidatos, sus partidos y sus propuestas.

En comparación con ello los años 1994 y 2003 se caracterizaron por ofrecer información al lector básicamente a partir de notas breves, las cuales, dicho sea de paso, no aparecen en la clasificación de géneros concebida en el Manual de Redacción del diario, y en las cuales no se logra profundizar sobre los detalles del proceso electoral, las características de los candidatos y mucho menos sus propuestas programáticas. En ambos casos, la proporción del uso del género de la noticia aparece en un segundo lugar, mientras los editoriales y columnas de opinión pasan a ocupar un lugar muy secundario en relación con lo que sucedió en el primer año del estudio. Se destaca igualmente en estos dos 
años el hecho de que se utilizarán de manera importante extensos pie de foto como información complementaria al recurso visual de la fotografía, información escrita que sin embargo tampoco ofrece mayor profundidad a la opinión pública.

Lo anterior permite además entender que el hecho de que haya habido mayor cantidad de notas periodísticas sobre el tema de elección popular de alcalde en los años 1994 y 2003, no necesariamente implica un mejor cubrimiento de la información electoral, toda vez que muchas de ellas fueron simples notas breves, mientras la menor cantidad de notas en 1988 se ocupó con mayor profundidad del hecho noticioso.

\section{Información electoral según géneros periodisticos por periodo}

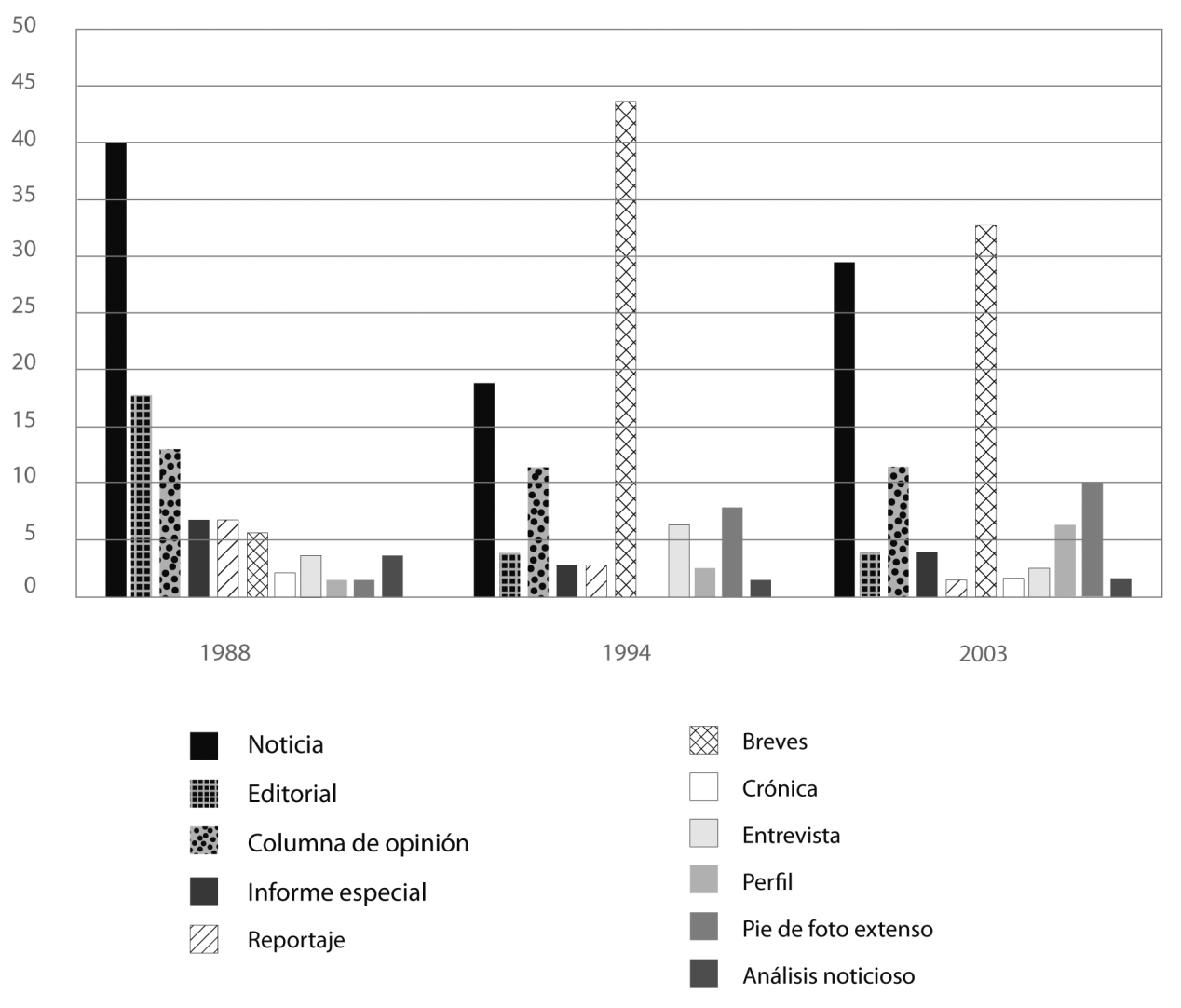

Gráfico 7. 
El muy escaso uso en los tres períodos del estudio de los géneros de entrevista, reportaje, análisis noticioso e informe especial, dan cuenta en general de un periodismo de poca profundidad, que hace uso de los recursos más básicos del oficio para ofrecer la información política relativa a las elecciones. Ello llama la atención toda vez que en el Manual de Redacción de El Liberal, en su capítulo VI se señala que "El género es una modalidad expresiva que facilita el tratamiento metódico del periodismo de información. Facilita la aplicación adecuada del método periodístico y propicia la aproximación hacia la objetividad y el realismo" (El Liberal, 1995, pág 15) y además reconoce que cuando se habla de géneros periodísticos de carácter informativo, se refieren "básicamente a la Noticia, La Entrevista, el Reportaje y la Encuesta” (El Liberal, 1995, pág 15).

Toda la información relativa a esta variable en los tres años de estudio, nos muestra en general un periodismo incipiente en relación con los géneros periodísticos, pero que además viene en descenso, ya que en el primer proceso de elección popular de alcaldes, se encontraron mayores evidencias de un tratamiento de mayor profundidad, gracias al privilegio del uso de géneros periodísticos que así lo permiten.

\subsection{Elementos contextuales}

En cuanto a la presencia o no de elementos de contexto en las notas periodísticas registradas sobre los procesos electorales, encontramos que comparativamente hubo una mayor contextualización en el año 1994 que los otros dos años del estudio, en los cuales sin embargo hay una diferencia importante: en 1988 fueron más las notas que sí tuvieron elementos de contextualización que las que no, mientras en el año 2003 fueron más abundantes las notas periodísticas sin contexto de la información, mostrando un detrimento de la calidad del cubrimiento en términos de la profundidad de la información que los elementos contextuales implican.

Esta observación es especialmente importante toda vez que la información electoral requiere quizá mayor análisis y contextualización que aquella que compone las agendas noticiosas cotidianas, en tanto es información que debe proporcionar al lector elementos de juicio para la toma, transformación, o ratificación de su decisión política.

\section{Gráfico 8.}

\section{Presencia o no de contexto de información por periodo}

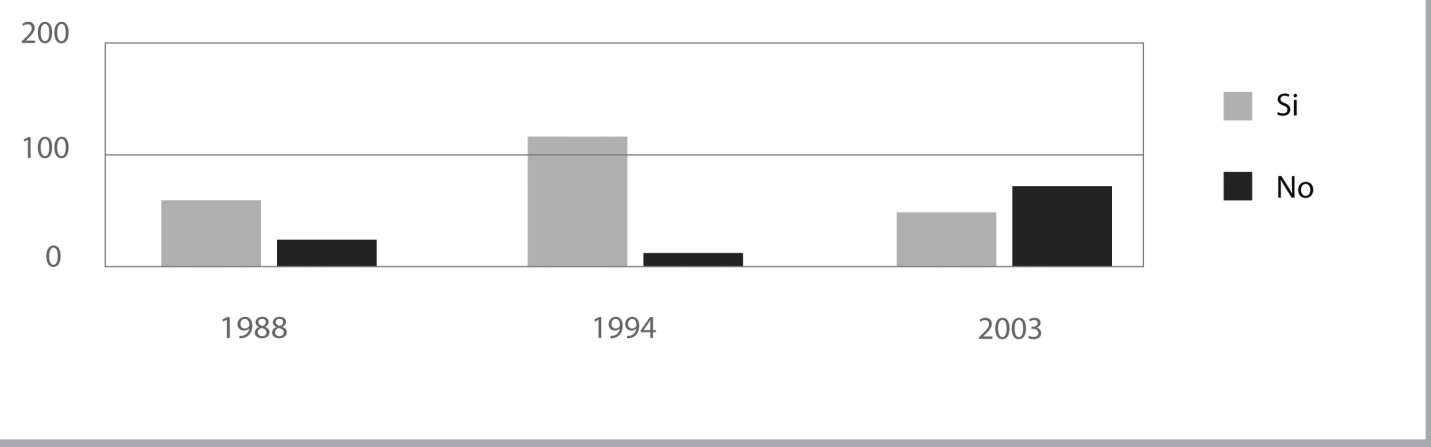


Al examinar comparativamente la distribución de frecuencias de los tipos de contexto asignados a la información periodística relacionada con el proceso electoral de alcaldes en cada año, encontramos que los dos primeros años del estudio, es decir 1988 y 1994, se caracterizaron por utilizar la relación con otros hechos similares o algunos datos complementarios del presente, prácticamente como el único tipo de contextualización posible. La revisión de elementos del pasado como antecedentes, o bien un análisis prospectivo de posibles consecuencias de los hechos de la noticia, resultaron prácticamente ausentes, aunque en una mínima proporción en el segundo período, es decir en el año 1994, algunas consecuencias fueron presentadas en las notas.

En el año 2003 en cambio, si bien hubo menos notas con contexto, aquellas pocas que lo presentaron tuvieron con claridad un mayor uso y una mayor variedad de tipos de elementos de contextualización para el cubrimiento del proceso electoral de alcalde de Popayán, incluyendo datos de presente, datos del pasado, y posibles consecuencias a futuro. Adicionalmente, algunas de dichas notas combinaron varios de los elementos de contexto, proporcionando con ello mayores datos al lector en torno a la información electoral, mirando los hechos desde diversas perspectivas.

Gráfico 9.

Tipo de contexto de la nota según periodo

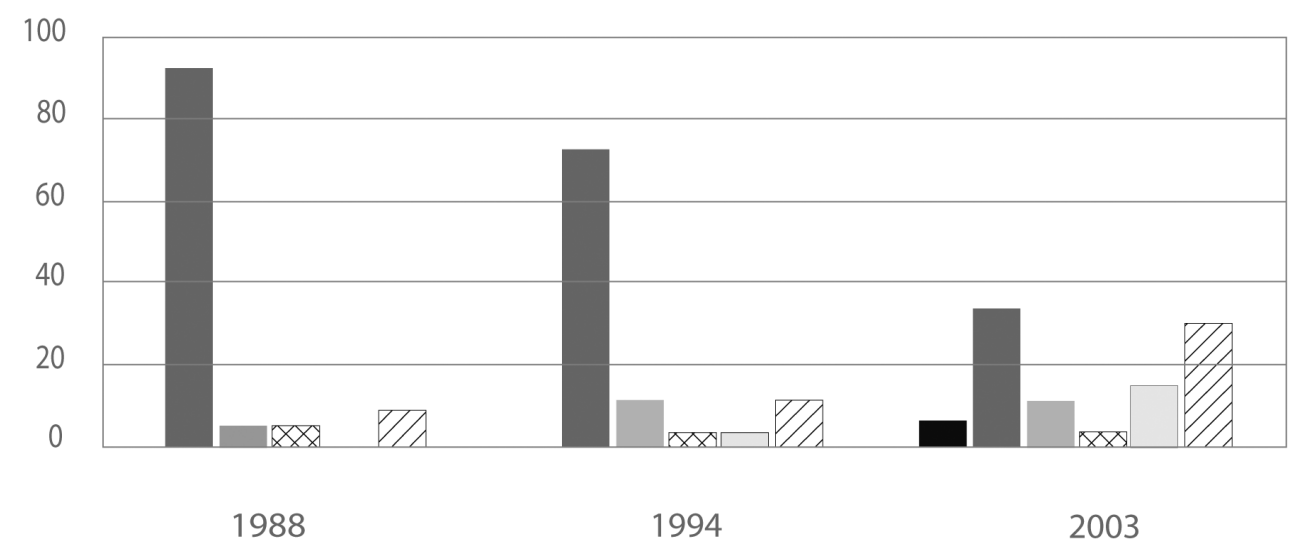

- Da antecedentes del pasado

Relaciona el hecho con otros del presente

Señala consecuencias del hecho
\& Da antecedentes y relaciona con otros del presente

Da antecedentes y señala consecuencias

प Relaciona con otros del presente y señala consecuencias 


\subsection{Fuentes de información}

El detalle sobre el tipo y la cantidad de fuentes de información utilizadas en el periódico para referirse a las elecciones a la alcaldía en los tres periodos de estudio, se revisa en el segundo capítulo, dado que involucra a los candidatos en contienda como fuentes de información. No obstante, puede decirse aquí que en general, El Liberal mejoró entre el primer y el segundo periodo de estudio el manejo de la información electoral en lo relativo al tema de las fuentes, pues disminuyó el porcentaje de notas periodísticas cuya fuente no se identifica (pero no por ser anónima, sino porque no es citada de alguna manera), aunque las cifras de dicha ausencia continúan siendo altas. Es así como en 1988 la inexistencia de fuentes se dio en el 40\% de las noticias sobre las elecciones; en 1994 en $12 \%$ de ellas y en 2003 en un $15 \%$.

Pero de otro lado, teniendo en cuenta que uno de los principios básicos de redacción, consagrados en el capítulo III del Manual de Redacción de El Liberal reza que "En cualquier caso, las noticias o informes deberán contener por lo menos dos fuentes informativas” y más adelante el mismo documento señala que "(...)No habrá excusa para escribir los artículos con base en lo que dice una sola fuente” (El Liberal, 1995, pág 11), es preocupante el hecho de que en los tres periodos la mayoría de las notas tuvieron únicamente una fuente de información, como se muestra en el siguiente gráfico.

\section{Distribución de número de fuentes de información por nota según periodo}

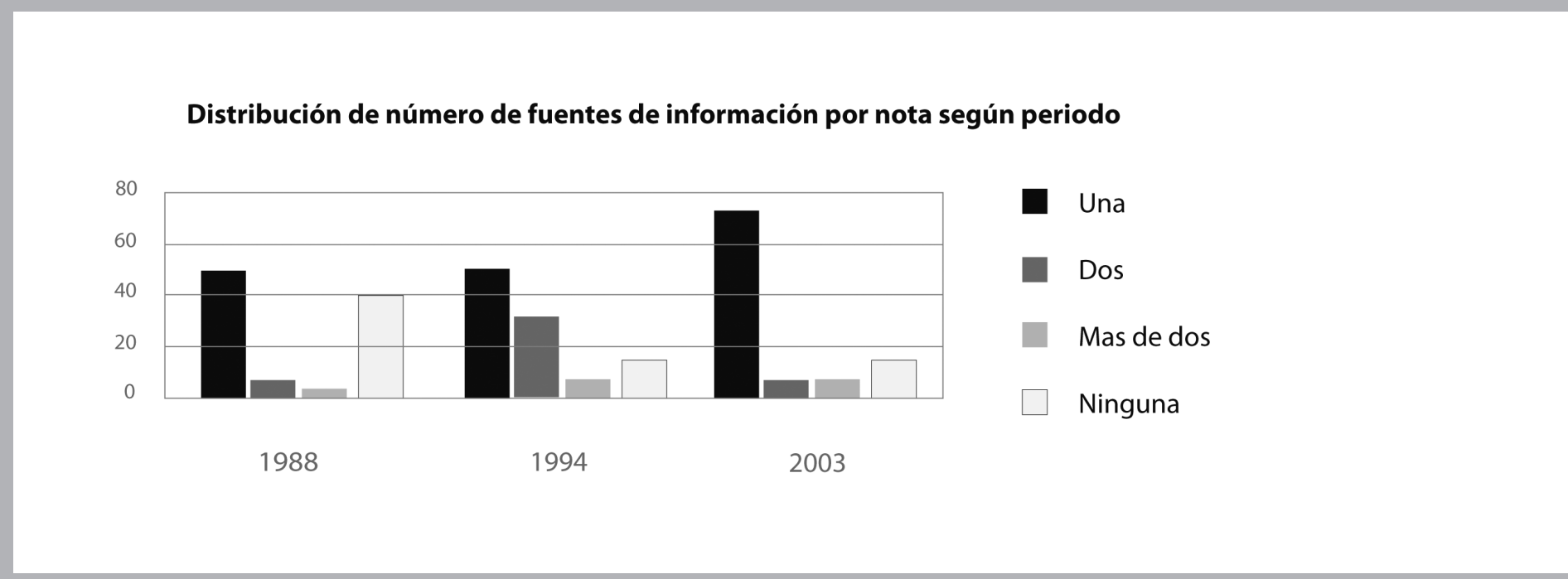

Gráfico 10.

Se examinó también la variable variedad de fuentes, es decir, si el periódico se basó en informaciones provenientes de diversas instancias combinando como fuentes por ejemplo, instituciones o personajes del sector oficial, pero también del privado, de la sociedad civil o fundamentándose también en documentos, o si por el contrario se basó en un solo tipo de fuente. Se encontró que en general hubo en el manejo de la información electoral poca variedad de tipos de fuentes; ahí donde las noticias tenían no una sino varias fuentes, en la mayoría de los casos estas eran del mismo tipo, es decir, fuentes solo estatales, o solamente de los propios partidos o candidatos, 
mientras la sociedad civil, las ONG, las fuentes de carácter documental, fueron poco utilizados como base para la generación de información en el proceso electoral, de acuerdo con los tres momentos de estudio revisados.

\section{Equilibrio informativo}

Nos referimos aquí al "equilibrio informativo" como aquel tratamiento periodístico del proceso electoral que se caracteriza por la presencia de indicadores que promuevan en el lector el ejercicio democrático del voto, gracias al suministro de información sobre la totalidad de candidatos en contienda, mostrando en profundidad en cada caso, sus propuestas programáticas y evitando sesgos valorativos tanto con la redacción de las notas como con la ubicación estratégica de la propaganda política.

En consecuencia, se examina a continuación cómo fue el comportamiento en los tres periodos de estudio, para el caso de El Liberal, de variables como candidatos mencionados, espacio asignado a cada candidato, temas relacionados con los candidatos, fuentes de información y simultaneidad entre propaganda política y notas periodísticas.

\subsection{Candidatos mencionados}

Para la primera elección popular de alcalde de Popayán, es decir en 1988, el desequilibrio informativo de El Liberal fue mucho más evidente que en los otros dos años del estudio, ya que más de la mitad de la información fue dedicada a al candidato Rodrigo José Zambrano, del Movimiento de Convergencia Liberal, mientras la otra mitad de la información se distribuyó entre los otros siete candidatos de la contienda. No obstante, más de una cuarta parte de la información se distribuyó entre sólo dos de los candidatos a saber: José Sebastián Silva del Partido Social Conservador en alianza con el Movimiento de Convergencia Ciudadana, y Felipe Llano Caicedo, del Partido Liberal Colombiano.

\section{$\%$ Candidatos mencionados 1988}

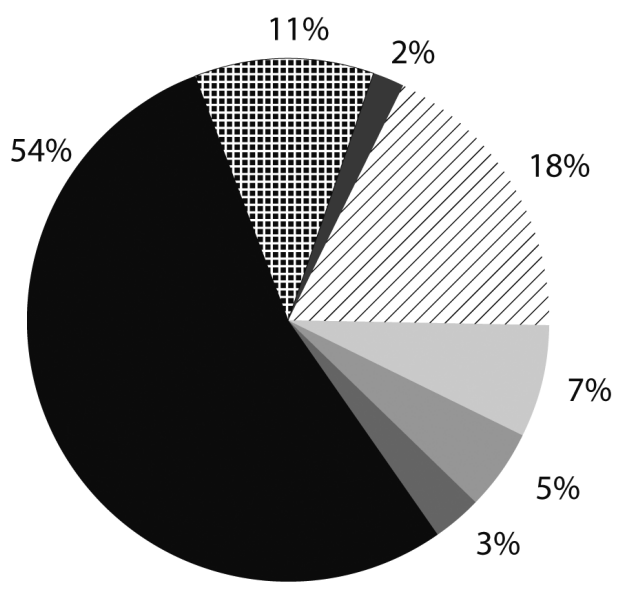

䎴 Felipe Llano Caicedo

José Dolores Daza

\# Juan Sebastián Silva Iragorri

- Juan Cristobal De la Torre

Maria Eunice Meneses

Melba Lizalda de Quintero

- Rodrigo José Zambrano

Gráfico 11. 
En 1994, con la presencia sólo de dos candidatos uno por el Partido Liberal y otro por el Partido Conservador, El Liberal distribuyó las menciones a los candidatos de manera totalmente equitativa $(50 \% \mathrm{c} / \mathrm{u})$, mientras en el 2003, los ocho candidatos a la alcaldía de Popayán fueron mencionados de manera distinta, distribuyéndose el 93\% de las notas periodísticas en tan sólo cuatro candidatos: Diego Gerardo Llanos, del Movimiento de Integración Popular, Felipe Fabián Orozco, del Movimiento Equipo Colombia, Marta Mercedes Castrillón, del Movimiento Cívico Independiente (quien recibió además en la mitad del proceso la adhesión de José Luis Diago y su electorado) y Víctor Libardo Ramírez, del Partido Liberal. Estos candidatos eran, de acuerdo con las encuestas y su trayectoria, los más opcionados a acceder al cargo de alcalde de la ciudad de Popayán.

Lo anterior ilustra que en torno al cubrimiento de los distintos candidatos en las contiendas electorales El Liberal hizo con el paso del tiempo un cubrimiento menos inequitativo, aunque no puede hablarse de un total equilibrio hacia cada uno de los aspirantes a la alcaldía, ya que en todo caso como se muestra en el año 2003, será especial tratamiento a aquellos que públicamente son considerados candidatos con más opción de acceso a la alcaldía, en general aquellos ligados a organizaciones partidistas de mayor trayectoria o a líderes de mayor reconocimiento por la tradición política nacional y regional.

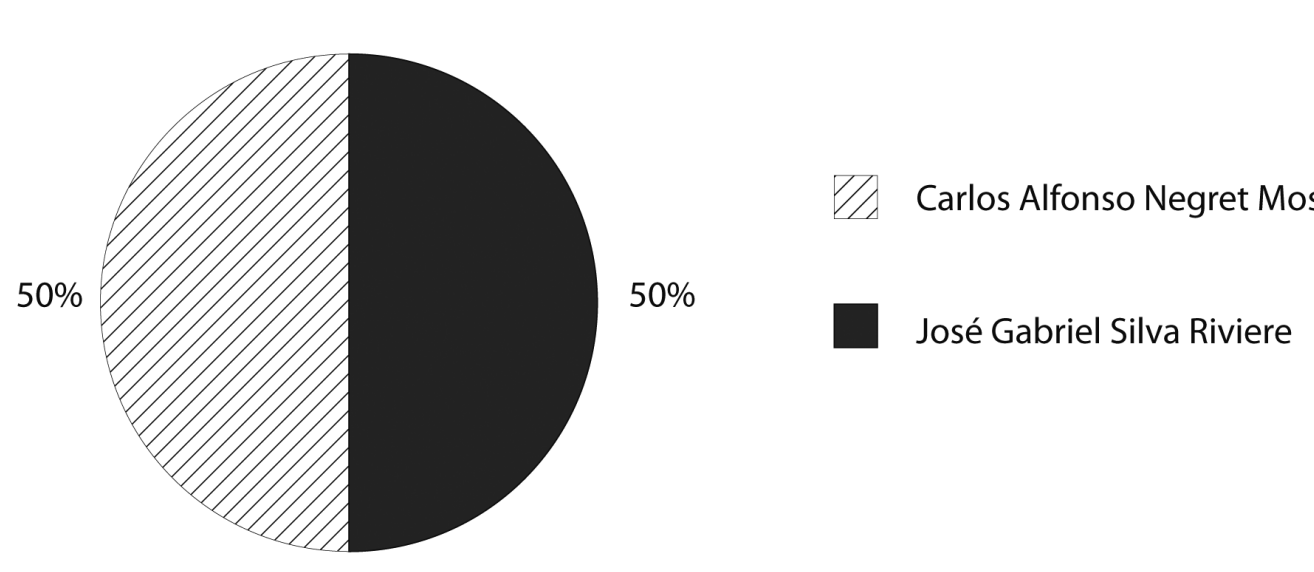

Gráfico 12. 
\% Candidatos mencionados 2003

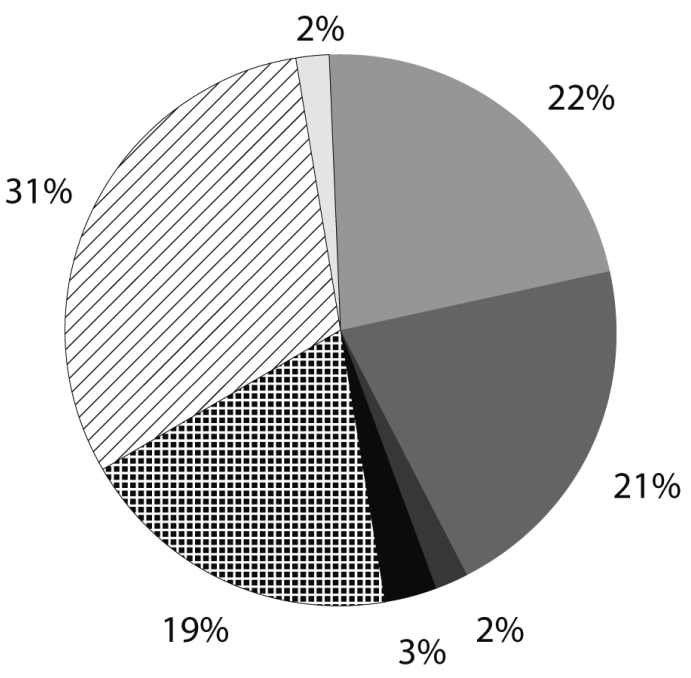

Diego Gerardo Llanos

Felipe Fabián Orozco

Gisela Delgado Tejada

José Luis Diago

帚 Marta Mercedes Castrillón

Victor Libardo Ramírez

William Fernando Pechené

\section{Gráfico 13.}

\subsection{Espacio asignado por candidato y partido}

La variable espacio de intervención se midió en $\mathrm{cm} 2$, y se refiere expresamente al espacio en que es la propia "voz" del candidato la que es reseñada, como elemento constitutivo de las notas informativas. En las elecciones populares de alcaldes en Popayán de los años 1988, 1994 y 2003, El Liberal informó ofreciendo a los candidatos espacios de intervención también inequitativos, exponiendo un criterio diferencial frente a la importancia asignada a cada uno de ellos así como a sus respectivos partidos.

En 1988, el caso de la primera elección popular de alcaldes se privilegió en el espacio de intervención a los mismos dos candidatos destacados en las menciones de las notas periodísticas: el del Movimiento de Convergencia Liberal, Rodrigo José Zambrano, en la línea política del periódico, y el de la coalición realizada entre el Partido Social Conservador y el llamado Movimiento de Convergencia Ciudadana, José Sebastián Silva, es decir, aquellos de orientación más convencional y cuyos partidos tienen una mayor trayectoria histórica en el país. No obstante, las diferencias entre los espacios asignados ameritan ser resaltada, pues mientras al aspirante Zambrano, por ejemplo se le destinaron en total durante el proceso electoral $2667 \mathrm{~cm} 2$, otros dos de los candidatos solo recibieron menciones en $5 \mathrm{~cm} 2$ cada uno. 
El privilegio del Partido Liberal Colombiano fue reiterado en los otros dos momentos de estudio y podría pensarse que corresponde políticamente a los lineamientos ideológicos del diario. No obstante, según la misión de la empresa consignada en su más reciente Manual de Redacción, actualizado en 1995 "El Liberal es una empresa caucana de comunicación masiva, de espíritu tradicionalmente liberal” (El Liberal, 1995, pág 6), lo que se refiere más que a una preferencia partidista, a una posición ideológica, acorde con las ideas liberales en términos más filosóficos que políticos, aunque claro, lo uno está relacionado con lo otro. Puede considerarse entonces que dicha prioridad del Partido Liberal obedece más bien una inercia por una historia ya recorrida, en la que sin duda como muchos otros periódicos del país, encontramos la expresa articulación entre los orígenes del periodismo escrito y la consolidación de los hoy llamados partidos políticos tradicionales ${ }^{3}$.

Es así como en 1994 la información fue en su orden para los candidatos del Partido Social Conservador, Carlos A. Negret y el del Partido Liberal, José Gabriel Silva, mientras en 2003 las intervenciones más extensas fueron para el Movimiento Cívico Independiente Martha Mercedes Castrillón y el Partido Liberal Colombiano, Víctor Libardo Ramírez. Se pone en evidencia entonces la constante del Partido Liberal como protagonista permanente de los procesos electorales, aunque no siempre sus candidatos estén en primer lugar en las encuestas de favorabilidad.

Como lo plantea Eduardo Gómez, quien fuera director del periódico entre 1983 y 1986, el nexo político de El Liberal con el partido de su mismo nombre, es mucho más evidente antes de los $90^{4}$, cuando aún el periódico no era una más de las 7 empresas periodísticas propiedad de Alejandro Galvis Ramírez, en el sentido de que el apoyo era no sólo más explícito, sino dirigido a los candidatos de la oficialidad del partido:

"En el pasado, cuando había cierta línea de partido, hace 30 años, 25 años, todavía ocurrían episodios políticos en que había listas, candidatos de partido, digamos la oficialidad del partido. Entonces el periódico siempre fue afín a la oficialidad del Partido Liberal. Pero de un tiempo para acá eso se rompe, comienzan a aparecer partidos nuevos, que se llaman distinto, que son originados por el Partido Liberal pero que pasan a llamarse Partido de la U, o pasan a llamarse Cambio Radical, entonces ya esa oficialidad del Partido Liberal ya se desdibuja"s.

Debe destacarse no obstante, una tendencia a la pluralidad de voces en el periódico, toda vez que a diferencia del año 1988, en las elecciones de 2003 se destacan los espacios concedidos no solo a los dos ya citados sino a otros dos candidatos, en tanto los considerados como de menor juego político, son reconocidos también, aunque con una proporción mínima. En este año, es interesante notar que algunos partidos "nuevos", como el Movimiento de Integración Popular, el Movimiento Equipo Colombia, o el Movimiento Cívico independiente, tuvieron a través de sus candidatos espacios destacados en las notas periodísticas relativas a las elecciones de 2003. 
\% Espacio de intervención de los candidatos por periodo

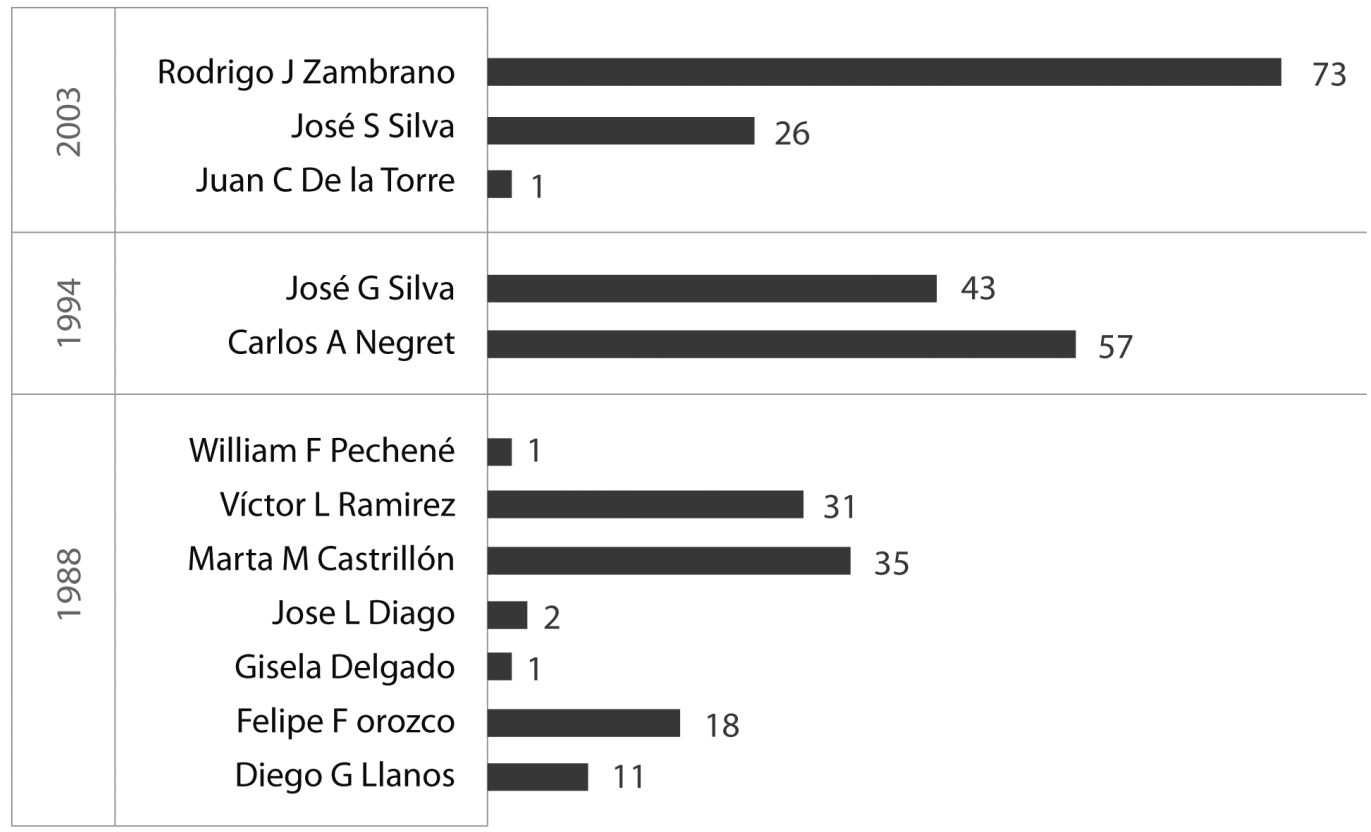

\section{Gráfico 14.}

\subsection{Temas mencionados, subtemas y candidatos}

El cubrimiento informativo de las distintas propuestas de gobierno expuestas por los candidatos se considera de vital importancia para ofrecer al lector datos claros acerca de los planes y proyectos que en los distintos sectores se proponen desarrollar en caso de resultar elegidos. Sin embargo, en los tres años del estudio, los correspondientes cubrimientos de las elecciones a la alcaldía de Popayán, fueron caracterizados por referirse fundamentalmente al propio proceso electoral (actividad proselitista, debates, alianzas, avales, etc) y no a los llamados temas programáticos. Así, en 1988 el proceso mismo ocupó un 66\% de la información electoral, en 1994 casi la totalidad, con un 96\% y en 2003 también una enorme mayoría (83\%). 


\section{Gráfico 15}

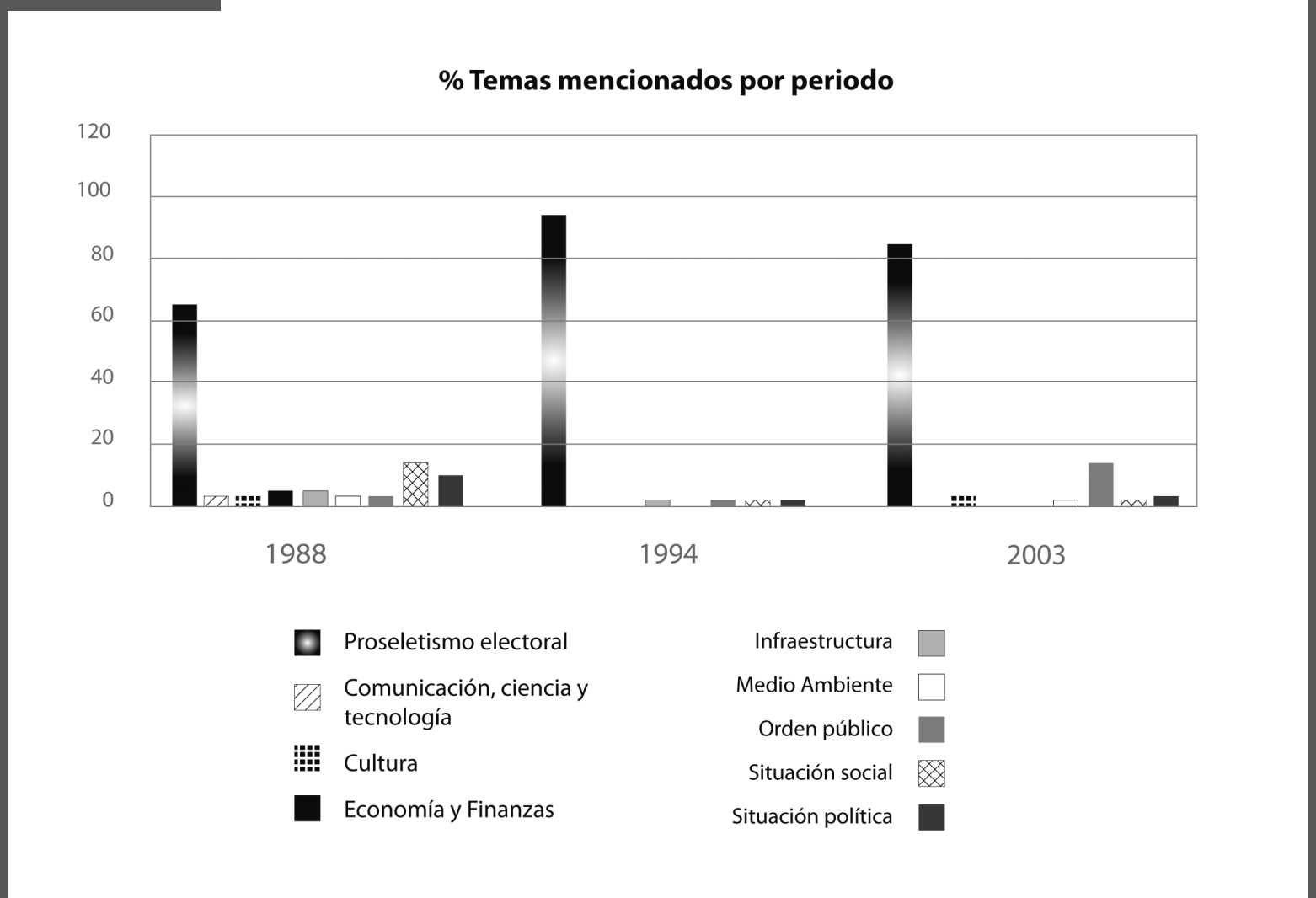

Los temas que secundariamente fueron informados a la ciudadanía dentro de las notas periodísticas relativas a las elecciones, fueron en 1988 la situación política y la situación social, apareciendo también unas pocas notas relativas a un abanico más o menos amplio de temas programáticos. En 1994, como se ha mencionado, la presencia de información distinta al proceso electoral mismo, es prácticamente inexistente y en 2003, el orden público, fue el tema en segundo lugar de importancia, con un 10\% de la información.

Esta variable muestra entonces una tendencia involutiva en El Liberal, en el sentido de que fue en el primer proceso de elección de alcaldes, en 1988, cuando se hizo para el caso de Popayán un mejor cubrimiento en términos de temas y los subtemas con los que se relacionó a los candidatos y al proceso electoral en general, al incluir por ejemplo el desempleo, la reforma política, los conceptos democráticos o la movilidad, como temas específicos de interés para el elector. La variedad de subtemas relacionados presentados en los tres periodos fue de 26 en 1988, 14 en 1994 y 22 en 2003.

Al revisar la misma variable en su relación directa con los distintos candidatos en contienda por la alcaldía en los tres periodos de estudio, encontramos que en 1988 los dos candidatos privilegiados fueron relacionados con temas distintos al proselitismo electoral, mostrando algunas de sus posiciones frente a asuntos programáticos tales como el empleo, la seguridad, la movilidad, la educación o la salud, aunque claro, el candidato de Convergencia Liberal, Rodrigo José Zambrano, quien como ya se dijo recibió más espacio y menciones, es quien se asoció también en las notas periodísticas con un más amplio abanico de temas, tal como lo muestra el gráfico 16. 


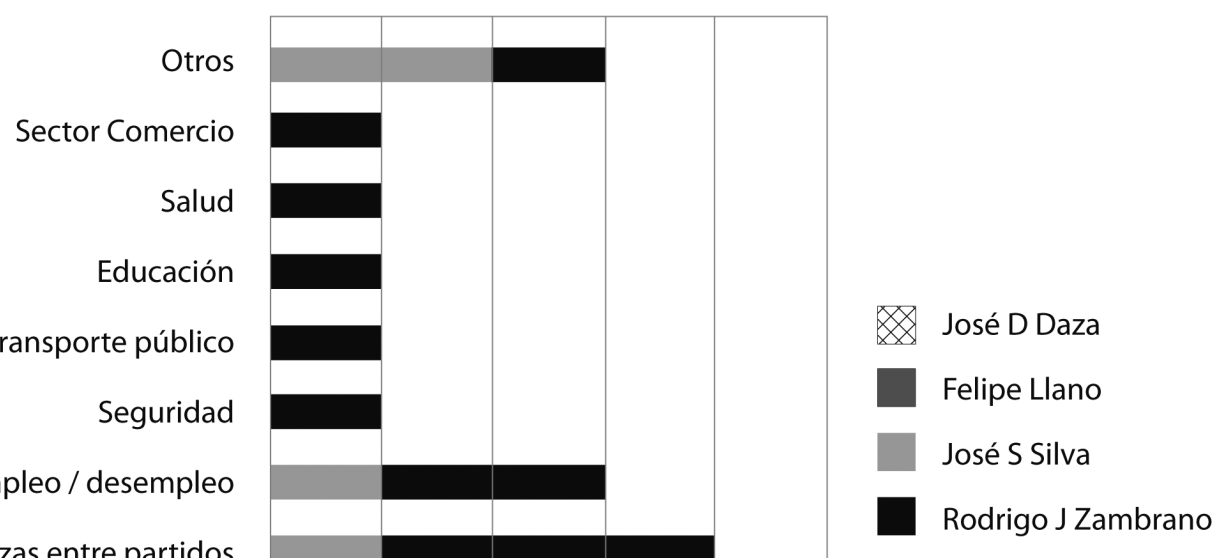

Avales o alianzas entre partidos

Comportamiento ciudadano

Debates

Proselitismo electoral

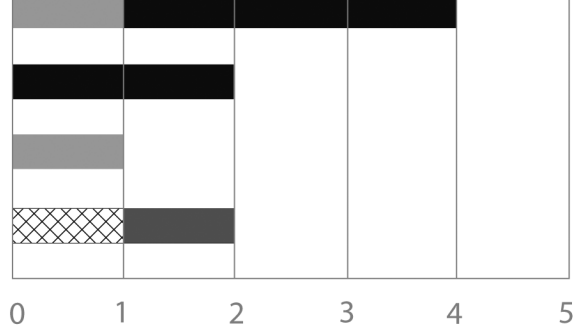

Para 1994 los únicos dos candidatos fueron relacionados con una variedad más o menos homogénea de temas, aunque en ambos casos, la actividad propia del proselitismo electoral fue el foco realmente fuerte de las notas periodísticas sobre el proceso electoral.

Subtemas mencionados por candidatos 1994

Otros

Recreación, espectáculo y deportes

Vivienda

Educación

Movilidad y transporte público

Seguridad

Empleo / desempleo

Comportamiento ciudadano

Debates

Proselitismo electoral

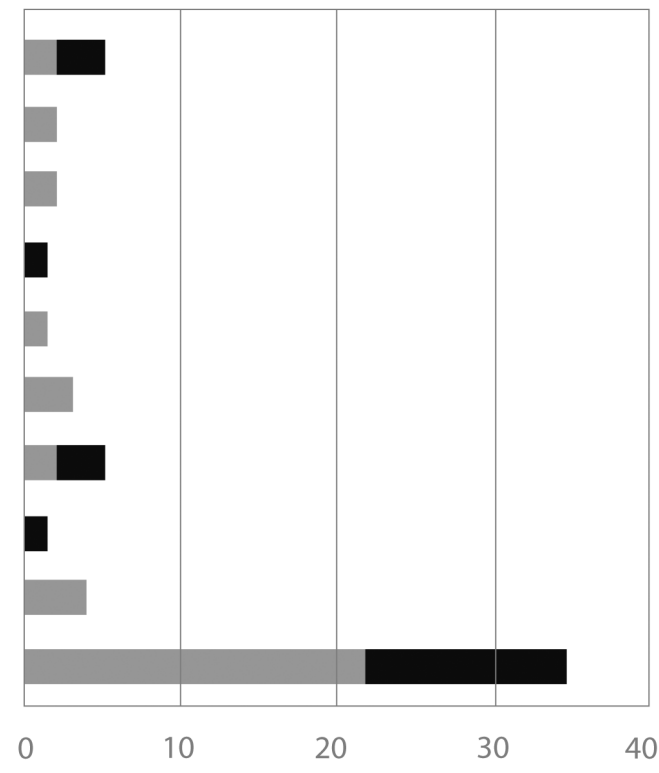

Carlos A Negret

José G Silva 
En 2003, los cuatro candidatos más mencionados y con más espacio asignado en la información periodística que cubrió las elecciones a la alcaldía de Popayán, fueron relacionados con al menos 8 temas de información, ofreciendo a la ciudadanía una perspectiva más clara sobre la variedad de sus programas de gobierno. Se destacaron en este periodo temas nuevos como el relativo a la acción de los grupos guerrilleros, tema neurálgico para la región y la ciudad, pero también un tema poco o nada trascendente para una decisión de carácter político, como la vida privada de los candidatos. La diversidad temática con la que se relacionó a la candidata Marta Mercedes Castrillón, del Movimiento Cívico Independiente, fue más amplia que la de los otros tres candidatos destacados, al incorporar por ejemplo las referencias relativas a la perspectiva de la candidata sobre el tema de vivienda y el de políticas culturales.

\section{Gráfico 18.}

\section{Subtemas mencionados según candidato 2003}

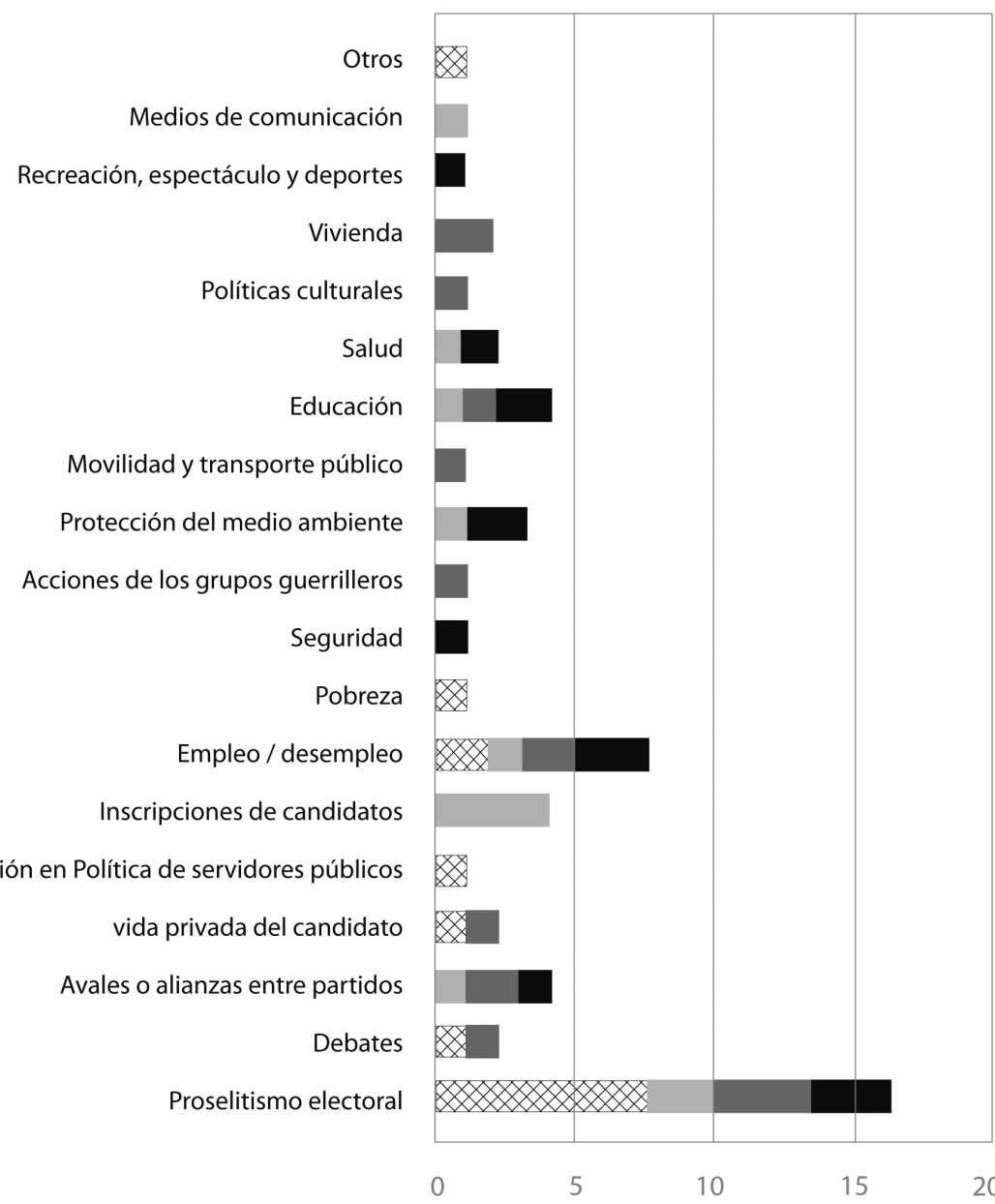

Diego G Llanos

Marta M Castrillón

Felipe F Orozco 


\subsection{Actores de la información}

Se encontró una constante en el análisis de la variable actores de información, toda vez que en los tres periodos de estudio las dos terceras partes de las notas recogidas sobre las elecciones a la alcaldía, tuvieron como actor principal a los propios candidatos, distribuyéndose la otra tercera parte en actores como la sociedad civil, los propios partidos políticos y los representantes del estado. Vale destacar que en el primer periodo, la representación de la sociedad civil como protagonista de la información fue ligeramente más alta que en los dos periodos subsiguientes. En 1988, el lugar secundario fue para la sociedad civil y los partidos, mientras que en 1994 y 2003, dicho papel lo ocuparon los actores estatales y la sociedad civil.

Es interesante que aunque con una baja participación, en el último año del estudio, es decir en 2003, los representantes de la Fuerzas Pública aparezcan como actores protagónicos de la información electoral.

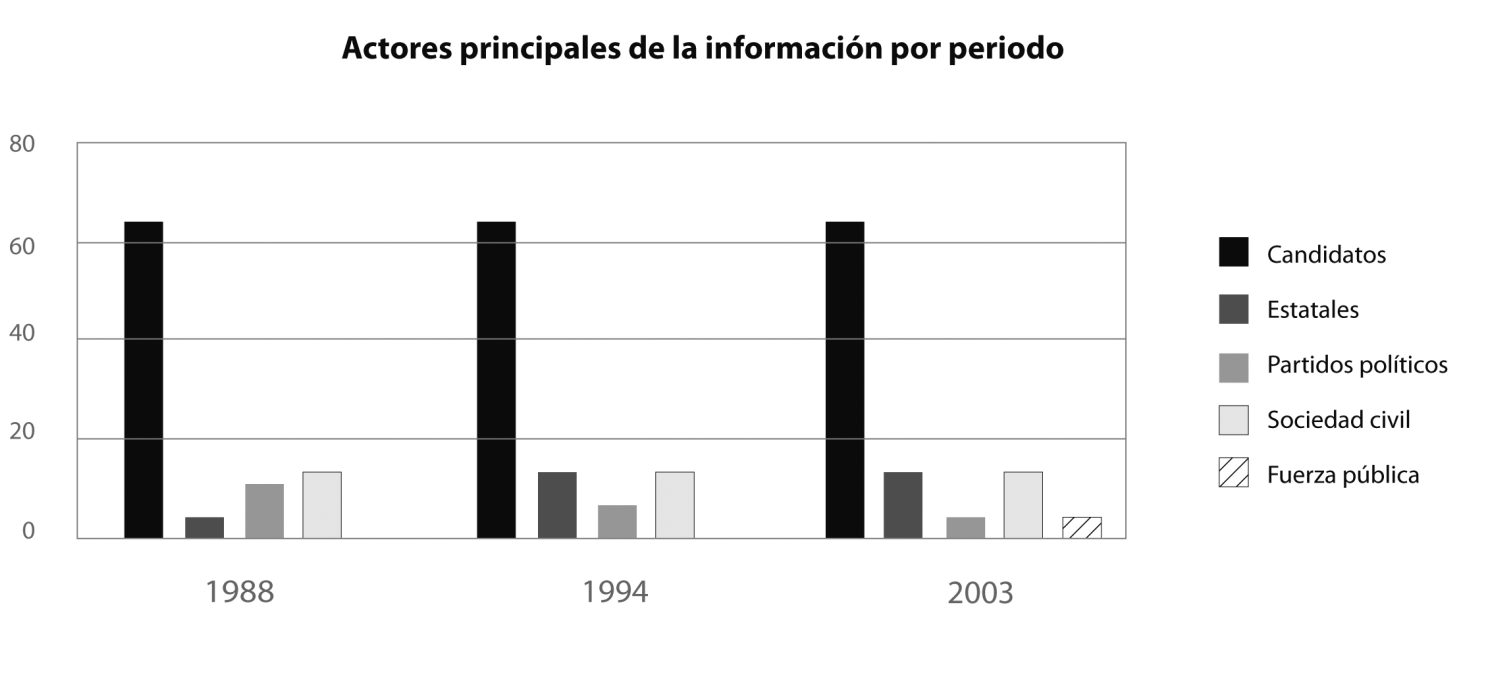

Gráfico 19.

\subsection{Candidatos como fuente de información principal}

Interesó igualmente para el análisis, la reflexión sobre quiénes fueron las fuentes principales de la información electoral sobre la alcaldía de Popayán en los tres momentos del estudio, y encontramos como suponíamos, que en efecto los candidatos en contienda ocuparon en los tres casos un lugar importante, pero que además dicho doble protagonismo - en tanto objeto de información y también como fuente de la misma -, tiene una tendencia creciente con el paso del tiempo.

Así, en 1988 los candidatos fueron fuente principal de la información en un 24\% de las notas de El Liberal sobre las elecciones a la alcaldía de Popayán, mientras en 1994 la proporción se incrementó un poco al ser el $27 \%$ de los casos y se hizo aún más importante en 2003 , con un $34 \%$. 
Distribución tipo principal de fuente de información por periodo

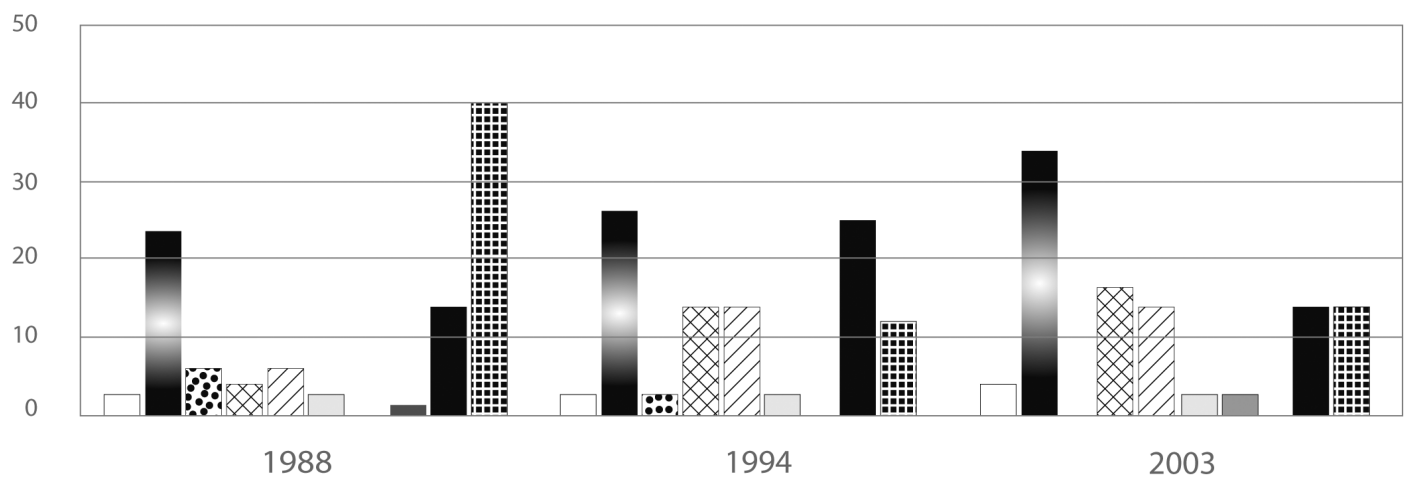

Anónima

0 Candidato en contienda

\% Vocero de partido en contienda

Institucional público

Z4 Personal público
Institucional privado

Personal privado

Especialista o experto en contienda

Otra

Ninguna

Otro dato que se destaca es que en suma, los funcionarios públicos y aquellos voceros de instituciones públicas, constituyeron la segunda fuente de información en las elecciones locales, también con tendencia a la alta. Para 1988, el 10\% de las notas se apoyó en fuentes del sector público, en 1994 la proporción fue de 30\% y en 2003 fue de 32\%.

\subsection{Proporción y simultaneidad de la publicidad política}

Finalmente, la revisión de la publicidad política en época electoral permitió identificar dos elementos: De un lado, las proporciones de publicidad por cada candidato en el periódico y su comparación con las proporciones de notas periodísticas emitidas por el diario en relación con dichos candidatos. De otra parte, la identificación de la simultaneidad en la ubicación de la publicidad de cierto candidato o partido, con la ubicación de las notas periodísticas relacionadas con dichos protagonistas del proceso. Ambas cosas, sirvieron para analizar la posible relación entre el apoyo a los candidatos y la pauta como elemento financiador de la empresa periodística lo cual se consideró importante pues dejaría entrever el manejo de mayor o menor independencia del diario. 


\section{Gráfico 21.}

En el análisis de los datos se pudo inferir que la mayoría de la publicidad política de los distintos partidos o candidatos, compartía en la misma edición alguna nota periodística sobre los mismos actores, en los tres periodos del estudio. No obstante hay algunas especificidades; para 1988 en la primera contienda popular de autoridades locales, fueron más las pautas políticas que compartieron la ubicación en la misma página con información noticiosa sobre el candidato o partido, que las que no lo hicieron (14 contra 6), lo cual constituye sin duda un reforzamiento de la promoción a los mismos, por parte del periódico que es quien toma la decisión editorial de dónde ubicar la información periodística. En los dos periodos finales del estudio, la simultaneidad de pauta política e información sobre los candidatos o partidos, se produjo como lo muestra el gráfico, en la misma edición pero básicamente en páginas distintas.

\section{Distribución de número de fuentes de información por nota según periodo}

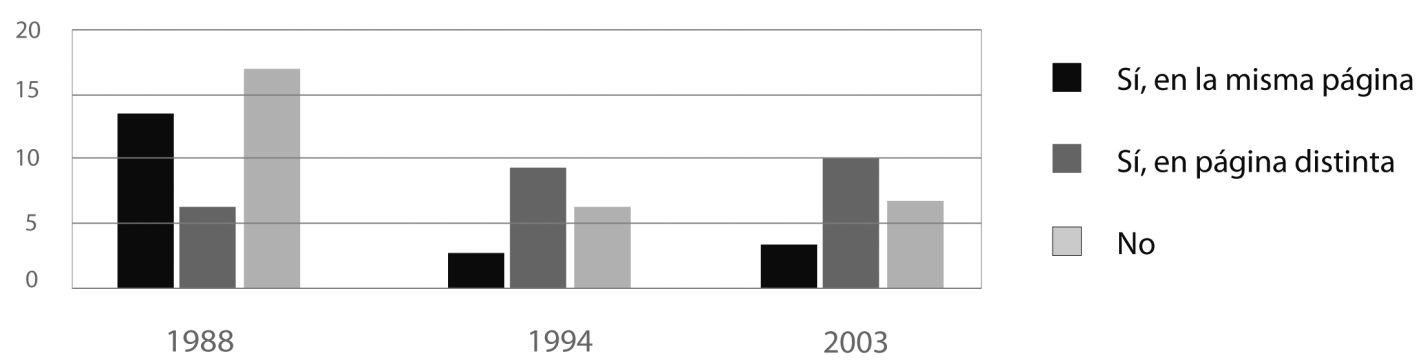

Ahora bien, revisando la cantidad de propagandas políticas que cada candidato publicó en El Liberal, encontramos que contrario a lo que podría esperarse, no fue el Partido Liberal el que en términos generales pautó más, pero hay diferencias importantes para mencionar comparativamente en los tres periodos de estudio. En 1988, coincide en el caso del candidato Rodrigo José Zambrano, Movimiento de Convergencia Liberal, la proporción más alta de las menciones (53\%) y también la más alta de las pautas (65\%). En ese año, el segundo candidato en importancia para el diario, José Sebastián Silva, de la alianza entre el Partido Social Conservador y el Movimiento de Convergencia Ciudadana, tuvo el $17 \%$ de las menciones y el 34\% de la publicidad política. No obstante, en el año 1994, es el candidato del partido Conservador, José Gabriel Silva, quien tiene la mayoría de las pautas (76.5\%), pero tiene exactamente la misma cantidad de notas periodísticas que el otro participante en la contienda, el liberal Carlos Alfonso Negret.

Finalmente, en 2003 los cuatro aspirantes destacados por el diario, fueron mencionados en proporciones relativamente similares en las notas periodísticas, presentándose de mayor a menor importancia Víctor Libardo Ramírez, del Movimiento de Integración Popular, con 31\%, \%, Diego Llanos de Equipo Colombia con 22\%, Felipe Fabián Orozco del Partido Liberal con 21\% y Marta Mercedes Castrillón, del Mov Cívico Independiente, con 19\%. Entretanto, las propagandas políticas de los candidatos que fueron publicadas se distribuyeron proporcionalmente así: 32\% Diego Llanos, 26\% tanto Víctor Ramírez como Felipe Fabián Orozco y 16\% Marta Castrillón. 
La ausencia de una clara correspondencia entre las proporciones de la variable candidatos mencionados en las notas periodísticas y pautas por candidato, rebate o invalida la hipótesis de una eventual relación de dependencia comercial en el periódico, en el sentido de que el pautante político estaría determinando la abundancia o no de información periodística sobre el candidato referido.

\section{\% Publicidad por candidato según periodo}

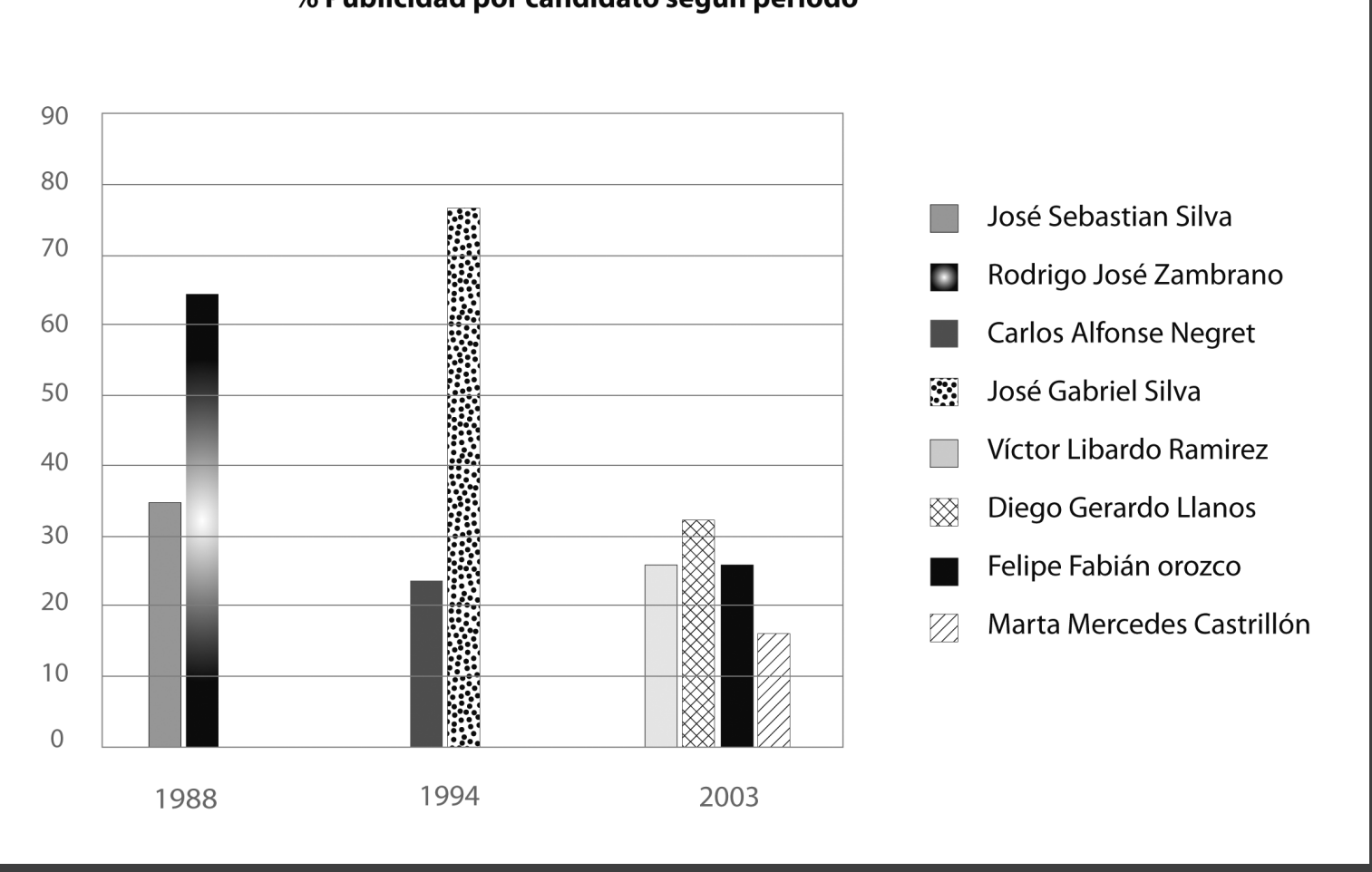

Gráfico 22

\section{Conclusiones y recomendaciones}

El análisis histórico realizado al periódico El Liberal en Popayán, no permitió identificar con claridad una línea editorial que haya trabajado de manera sistemática el mejoramiento del cubrimiento de la información política, en particular la relativa a los procesos electorales de alcaldes. Los tres periodos estudiados ilustran acerca de tres momentos distintos, en los que las variables crecen o decrecen pero no de manera sostenida, ni en coherencia con otras, como para lograr inferir tendencias específicas.

La ausencia de cambios significativos y persistentes entre el primer periodo y los otros dos, nos sugiere además que las transformaciones del periódico a partir de 1990, se redujeron al cambio de propiedad, al pasar la mayoría de sus acciones a manos de Alejandro Galvis, y a modificaciones tecnológicas al reemplazar el linotipo por la redacción digital y la impresión en rotativa. 
Algunos rasgos en cambio, en particular sobre los procesos electorales, permiten hablar de un periodismo político relativamente descuidado, en tanto cada vez privilegia las notas breves, sobre los análisis en profundidad o la información contextualizada. Podría pensarse que el mayor uso de la noticia y las breves, y la ausencia creciente de notas firmadas, daría cuenta de un incremento de aquellas que Miguel Ángel Bastenier denomina notas secas.

"La nota seca tiene la mayor distancia del hecho, por eso tiene el grado mínimo de interpretación posible por parte del autor. Tiene los elementos suficientes para que el lector tenga una idea clara de lo que está sucediendo. La materia prima de la nota seca son el teletipo, las circulares, los boletines, las notas de prensa. A partir de ello se construye una información en la que el autor no tiene derecho a interpretar nada porque no ha visto nada ni ha estado en el lugar de los hechos (...) y por eso la nota seca no se firma." (Gaviria, 2004, pag 8).

Del mismo modo, la poca utilización de recursos visuales infográficos para el caso de los procesos electorales, da muestras de un periodismo con poca investigación, en el momento en que mayor información sobre los candidatos y sus propuestas debe ser expuesta con claridad para fomentar un voto consciente por parte de la ciudadanía.

Si bien algunos autores consideran que hoy en día la prensa está conminada a elegir entre presentar información del mundo para el mundo o presentar información regional, pertinente solo para la formación más directamente involucrada en cierto territorio geográfico y cultural, la última opción - que podría ser la de un periódico como El Liberal -, no exime al periodismo de su responsabilidad de trabajar con claridad, profundidad y contexto, los temas que como los procesos electorales, requieren de información para fomentar el ejercicio consciente de la democracia.

La época electoral también es un tiempo de reflexión y revisión ciudadana sobre los gobernantes y las políticas oficiales que se estén llevando a cabo, y los medios de comunicación son cruciales para incentivar y enriquecer este debate. El tiempo de campaña debe ser plural, diverso, de múltiples voces, Iluvias de ideas; un espacio para reflexionar si en nuestras ciudades y pueblos, en el campo, en el país, estamos construyendo el tipo de sociedad que queremos.Y, por supuesto, para descubrir qué debemos hacer para cambiarla (Ronderos y Moreno, 2011, pág 5).

Por lo anterior, ahora que ha sido objeto de un proceso de renovación, El Nuevo Liberal está llamado a realizar modificaciones importantes en el cubrimiento de futuros procesos electorales, aportando con mayor decisión a la formación de una opinión pública basada en criterios y la construcción de una ciudadanía con elementos políticos para el ejercicio democrático del voto. 
Se sugiere para ello por ejemplo, recuperar la pluralidad de fuentes como una de las herramientas básicas del buen periodista, incorporando además de los candidatos, los partidos y las autoridades electorales, a las organizaciones sociales, a las ONG, a los líderes ciudadanos, trabajadores, representantes gremiales y empresariales, etc, como voces fundamentales que demandan de los candidatos y sus procesos de campaña claridad sobre sus propuestas, programas o planes de trabajo, y que proporcionan también información de primera mano sobre el estado de las localidades, los municipios y el departamento como testigos directos de las situaciones, en función del ejercicio de la democracia.

De hecho, en procesos electorales El Liberal como medio impreso, pero en general todos los medios, pueden promover la participación a través de encuestas ciudadanas sobre expectativas frente al manejo de los que son percibidos como problemas sensibles en localidades, municipios o el departamento. Dichas encuestas pueden recoger también las ideas de la comunidad acerca de las posibles soluciones a dichos problemas y los compromisos que corresponden tanto a las autoridades públicas como al sector privado y a la sociedad civil. Dicha movilización de opinión ubica al medio en un lugar privilegiado como dinamizador de debates útiles para la construcción o mejoramiento de propuestas programáticas por parte de los candidatos en contienda.

Superar el unifuentismo detectado a nivel nacional como una tendencia en el manejo de la información periodística relativa a los últimos procesos electorales ${ }^{6}$, con un esfuerzo por la búsqueda de multitud fuentes, es lo que proporcionará amplitud de criterios para que los lectores puedan informarse con claridad y profundidad sobre tan importantes coyunturas políticas como lo son los procesos electorales.

Adicionalmente, es importante fortalecer la contextualización de la noticia, y evitar las notas breves (secas) que pocos datos arrojan al día a día del proceso de campaña y al resultado final esperado: el de una masiva asistencia a las urnas en la que cada ciudadano acuda con clara conciencia de su decisión. Develar periodísticamente cuáles son los intereses que pueden estar en juego en una campaña, las luchas de poder, las posibles crisis que se están disputando en la definición de futuros mandatarios, los modelos de cada partido para afrontar las situaciones problemáticas, son fundamentales para tener un panorama completo del juego político del proceso. Como plantean Ronderos y Moreno, "Hay ideas de los candidatos desinteresadas y fundamentadas en el bien público. Pero otras no tanto. Por eso los periodistas deben ser críticos y tener toda la información de contexto posible para determinar qué hay detrás de las propuestas de los candidatos" (Ronderos y Moreno, 2011, pág 26). 
Sólo una contextualización adecuada, con la profundidad requerida, sobre los antecedentes, los temas convergentes y las proyecciones relativos a cada propuesta, proporcionará a los lectores y en general al público de los diferentes medios la posibilidad de debatir, discutir y comparar potencialidades y limitantes de candidatos y partidos en contienda. En ese sentido, las trayectorias de los candidatos, sus experiencias políticas previas y claro, sus antecedentes como trabajadores del sector privado, las fuentes de financiación de sus campañas, son datos básicos a ser indagados periodísticamente por el medio y analizados para el público lector. En este sentido, el ejercicio riguroso de una buena reportería, que recupere los contactos cara a cara aunque haga buen uso de las tecnologías de la información para agilizar su trabajo, es de vital importancia. Tal como lo plantea el Manual de Redacción de El Liberal en su Decálogo del buen reportero (el cual es tomado del Manual de Redacción de ElTiempo):"No deje que otros le cuenten su versión de los hechos. Salga a la calle, abra los ojos, pregunte. Recuerde que los mejores reporteros son los que tienen las mejores piernas, para visitar lugares, recoger datos, confrontar versiones”(El Liberal, 1995, pág 36).

En torno a los temas objeto de noticia en procesos electorales, si bien aquellos aspectos relativos directamente al proselitismo electoral constituyen obviamente base de las noticias diarias, los temas programáticos necesitan mayor atención, pero no en el sentido de que los medios - en este caso El Liberal -, repitan o hagan simple eco de aquello que ya en volantes, afiches y demás material de propaganda política las distintas campañas han difundido, sino que se avance hacia la confrontación de aquellos propósitos, a través del uso de géneros como la entrevista o el reportaje, en donde los responsables de dicho discurso puedan fundamentarlo con mayor contundencia, destacar el carácter innovador de sus planes y mostrar su conocimiento sobre las situaciones a intervenir.

El Liberal debe dar particular relevancia a aquellos temas programáticos que justamente se hayan destacado como de mayor sensibilidad para los distintos sectores sociales que constituyen la comunidad local, municipal o departamental, dependiendo del proceso electoral del que se trate. Algunos de esos temas han sido históricamente neurálgicos para nuestra región, como aquellos relativos al conflicto armado, el desempleo, la atención al campo, el desplazamiento o la pobreza, por lo cual la promoción del debate entre candidatos y entre estos y la comunidad, puede ser una importante contribución a la formación de opinión pública y a la definición de una agenda política pertinente.

Finalmente, manteniendo uno de sus principios informativos consagrados en el Manual de Redacción de El Liberal, el cual señala que "El lector tendrá prioridad sobre cualquier interés, incluido el de los anunciantes. EL LIBERAL diferencia muy bien en sus páginas cuando un texto tiene un objetivo publicitario, de uno noticioso. Los Departamentos de Redacción y de Publicidad son autónomos y no tienen en sí mismos relación de subordinación" (El Liberal, 1995, pág 10), es importante que el periódico mantenga una sana vigilancia en torno a la publicidad política pagada, evitando la publicación de la misma en páginas en las que existan notas periodísticas relativas al proceso electoral, independientemente de si dichas notas se refieren o no a la misma campaña publicitada. Así mismo, debe evitar en lo posible las diferencias excesivas entre las proporciones de publicidad de las distintas campañas. 
Aunque no depende del periódico que algunas campañas no estén interesadas o no tengan recursos para patrocinar publicidad en El Liberal, si puede el diario regular las proporciones de las que sí, procurando en la medida de lo posible un cierto equilibrio que muestre su intención de mantener distancia frente a las opciones políticas en juego.

\section{Notas}

${ }^{1}$ Socióloga. Magister en Comunicación y Diseño Cultural de la Universidad del Valle. Magister en Sociología. Profesora Asociada, Departamento de Comunicación Social, Universidad del Cauca. pruiz@unicauca.edu.co. Este artículo deriva del proyecto de investigación “Análisis histórico del tratamiento periodístico a la información electoral en el diario El Liberal. Tres momentos de estudio”.

${ }^{2}$ Los informes recientes de la FLIP muestran unas estadísticas con tendencia a la baja frente al asesinato de periodistas, pero mucho más graves y de manera creciente en cuanto a las amenazas y otras violaciones a la libertad de prensa en el Colombia. Véase al respecto: http: / www.flip.org.co/ resources/documents/2b6d51e2c5bbb78c3f17db0f34491ada.pdf

${ }^{3}$ En las primeras páginas del Manual de Redacción de El Liberal, se destacan algunos elementos importantes de su historia. Por ejemplo en la tercera página se dice que "El primer editorial del diario hacía referencia al nacimiento del nuevo medio de comunicación y al servicio que éste prestaría al departamento y a la ciudad. En esa sección del periódico se afirmó también que EL LIBERAL había sido creado como órgano al servicio del partido."

${ }^{4}$ En entrevista concedida el 1 de noviembre de 2011 a dos estudiantes de comunicación social de la Universidad del Cauca, Erika Jiménez y Luz Mery López, la exdirectora de El Liberal entre 2007 y 2009 y quien organizó el actual Manual de Redacción en el 95, afirmaba sobre el tema: "el periódico, si bien a comienzos de la época electoral asumía al comienzo que por quien votar, recomendaba por quien votar, ya no asumió las banderas del partido liberal. Hasta cuando llegó la familia Galvis, el periódico estaba ligado al directorio liberal del Cauca. Cuando los Galvis compran eso, ellos son empresarios de medios de comunicación, y no tienen nada que ver con los políticos, entonces se acabó. Eso implicó una lucha muy dura porque la gente seguía llegando allá a decir que sí, que sáqueme esto porque fulanito es liberal y es amigo del partido, eso se acabó. El periódico por primera vez le dio participación a columnistas que eran de otras corrientes políticas. Eso se me había olvidado, algo muy importante en la parte editorial. Se acabó la politiquería de partido allá, el periódico no tenía nada que ver con el directorio y si el directorio quería sacar algo, tenía que pagar un aviso o lo que fuera porque no. De El Liberal solo quedó el nombre, porque además quitarle el nombre a un periódico de tanta tradición pues ya era más difícil posicionar otra marca. Entonces se quitó eso a tal punto que hubo un momento en que llegaron a decir que el periódico era más conservador que liberal”(Jiménez y López, 2013).

${ }^{5}$ Entrevista concedida por Eduardo Gómez a Diego Imbachí, asistente de investigación.

${ }^{6} \mathrm{Al}$ respecto véase el documento publicado por la Misión de Observación Electoral, MOE en 2011 "El periodismo en las elecciones". 


\section{Referencias}

El Liberal (1995), Manual de Redacción, Popayán.

Fontcuberta, M. (2006), Simplificación periodística. La realidad como mosaico. Revista Cuadernos de información, (19) $30-35$, Barcelona

Gaviria, M. (2004), Relatoría del taller para nuevos editores dictado por Miguel Ángel Bastenier en la Fundación Nuevo Periodismo. Cartagena. 29 de marzo a 2 de abril de 2004. Recuperado el 15 octubre de 2013 del sitio Web: http:/ / portales.puj.edu.co/nmedios/periodismo/doc/ nuevoseditores.pdf

Jiménez, E.J. y López, L.M. (2013), Análisis sobre el tratamiento de las mujeres en el lenguaje utilizado por el diario El Liberal de Popayán en la construcción de las noticias publicadas en 14 ediciones de septiembre de 2010 a octubre de 2011. Primer informe de trabajo de grado para optar al título de comunicadoras sociales. Universidad del Cauca, Popayán.

Martínez, J. L y Santamaría, L. (1996), Manual de estilo. Recuperado el 15 de octubre de 2013 del sitio Web del Instituto de Prensa de la Sociedad Interamericana de Prensa: http://www. institutodeprensa.com/libros/estilo/1-60.pdf.

Misión de Observación Electoral - MOE. (2011), El periodismo en las elecciones. Bogotá: Torre Blanca Agencia Gráfica.

Restrepo, J. D. (2010), Responsabilidad social de la prensa. Recuperado el 16 de octubre de 2013 del sitio Web Oserí. Cultura y derechos humanos: http://uri.oseri.net/index.php?option=com_ content\&task $=$ view\&id $=606 \&$ Itemid

Ronderos, M.T. y Moreno, M. F. (2011) Cómo cubrir elecciones. Manual para periodistas. Bogotá: Editorial FESCOL.

Documento de trabajo de grado Erika Jiménez y Luz Mery López, “Análisis sobre el tratamiento de las mujeres en el lenguaje utilizado por el diario El Liberal de Popayán en la construcción de las noticias publicadas en 14 ediciones de septiembre de 2010 a octubre de 2011".

Recibido: octubre 30 / Aprobado: Noviembre 28 de 2013 